\title{
Resource Abundance, Political Corruption And Instability Of Democracy
}

Victor Polterovich, Vladimir Popov and Alexander Tonis

New Economic School

Moscow 2008 


\begin{abstract}
We analyze data on sustainability of democratic regimes in resource rich countries and suggest a model to explain why resource abundance may lead to instability of democracy in some countries, but does not create any difficulties for a democratic system in other ones.

Our central idea is as follows. If a country is abundant by point resources, this creates a prerequisite for resource owners to have dominant economic power. If institutions are weak under democracy, the economic power may be converted into political one. Resource owners ("oligarchs") can thrust their preferred decisions on a parliament, bribing politicians. This creates a base for a potential Autocrat's strategy to get power.

Rate of resource rent tax is considered as the only policy instrument in our simple model. The tax affects the income of a representative voter. Choosing a tax rate, Autocrat competes with conventional Politician (a representative political party) for the office.

Our model demonstrates the existence of a threshold for propensity to corruption such that the probability of the democracy preservation is decreasing in the amount of resources if the propensity is higher than the threshold and is independent of resources or even grows with the amount of resources if the propensity is lower. It is shown also that Autocrat may use two types of policies depending on the qualities of governance (abilities to allocate tax revenues without big losses) that the public assigns to her and to Politician. More efficient Autocrat is inclined to follow populist high tax policy whereas lower Autocrat's efficiency results in pro-Oligarch low tax policy when the country is resource abundant.
\end{abstract}




\section{Introduction}

Resource abundance is associated with lack of democracy. This observation was corroborated in a number of researches (Barro (1996, 1999), Ross (1999, 2001), Wantchekon (1999), Polterovich and Popov (2006)). These and some other papers try to explain the connection between resource abundance and authoritarianism. They point out three channels that decrease chances of opposition rise in resource rich countries, and therefore lead to higher stability of autocracy:

1). Autocrat's ability of financing enforcement structures (police, public prosecutor's office, army, secret service, etc.) to suppress protest movements and to protect her country from aggressors;

2). Autocrat's ability of setting low taxes and conducting social policies to reach people tolerance and prevent formation of opposition;

3). Underdeveloped social capital.

Robert Barro includes a dummy for OPEC countries (Barro, 1996) and a dummy for oil-exporting countries in accordance to the IMF definition (Barro,1999) and find their significantly negative influence on democracy indicators. He concludes "that the income generated from natural resources such as oil may create less pressure for democratization than income associated with the accumulation of human and physical capital." (Barro, 1999, p. 164).

Wantchekon (1999) argues that when the state institutions are weak, resource abundance tends to create incumbency advantage since an incumbent party may have private information about level of rents available for distribution or even discretionary power over distributive policies. In a model suggested by Wantchekon the opposition creates political unrest if it fails in the elections. The incumbent wins the elections only if she may use the rent to compensate possible voter's losses arising due to unrest. Thus incumbency advantage prevents any change of power, and this, by definition, leads to authoritarianism whereas the unrests result in political instability. The author presents an empirical analysis of incumbency advantage. By definition, the incumbency advantage took place if a democratic regime prevailed in a country, and during her current tenure in office, an "incumbent unconstitutionally closed the lower house of the national legislature and 
rewrote the rules in their favor". Regressions show that the incumbency advantage depends positively on ratios of primary export to GDP, and negatively on the values of Gini coefficients.

A comprehensive study of the oil-impedes-democracy hypothesis was done by Michael Ross (Ross, 2001). He used data from 113 states between 1991-1997, and found that resource wealth makes democratization harder. He also has found "at least tentative support for three causal mechanisms that link oil and authoritarianism: a rentier effect, through which governments use low tax rates and high spending to dampen pressures for democracy; a repression effect, by which governments build up their internal security forces to ward off democratic pressures; and a modernization effect, in which the failure of the population to move into industrial and service sector jobs renders them less likely to push for democracy." (Ross, 2001, pp.356-357). In fact, this study corroborates that all three channels mentioned above, really work against democratization.

Polterovich and Popov (2006) demonstrate that average share of net fuel import for 1960-1975 effects positively both democratization and government effectiveness indicators.

Egorov, Guriev and Sonin (2006) assumes that resource abundance increases incentives of a dictator to stay in power so that the success of economic policies turns out to be comparatively less important. Therefore, as their model shows, the dictator is less interested to control efforts of her subordinates, and consequently less interested in free mass media. The absence of free media hampers civil society development, which is the main prerequisite for democratization.

The fourth channel may exist due to mutual influence of resource abundance, institution quality and democratization. Lobbing, dishonest competition, corruption flourish in many resource abundant developing countries hampering economic growth (Auty (2001), Sachs and Warner (1999, 2001), Leite and Weidmann (1999), Bulte at al (2003), Lane and Tornell (1999), Torvik (2002), Wantchekon, and Yehoue (2002)). This is not the case, however, for advanced economies such as Norway or Canada. Moreover, recent researches, using more correct measures of resource abundance, longer time periods, and more sophisticated econometrics techniques, have challenged the resource curse hypothesis and have found that, on average, a resource rich country has not lower GDP per capita than resource poor one with similar other characteristics (Rodriguez, Sachs (1999), Alexeev, Conrad (2005), Stijns (2005), Acemoglu et al (2005), Brunnschweiler, C. N. (2006)). To 
explain these facts, a threshold hypothesis was suggested and studied in a number of papers both theoretical and empirical ones. The hypothesis claims that the resource curse takes place if and only if institutional quality does not exceed a threshold level that depends on the resource quantity (Mehlum, Moene and Torvik (2005), Robinson, Torvik and Verdier (2006), Zhukova (2006), Kartashev (2006)). At other hand, our recent paper (Polterovich, Popov, 2006) implies that, under weak institutions, democratization results in their further deterioration and therefore decreases rate of growth. Thus resource abundance raises chances for a country to have weak institutions, therefore democratization may worsen them further giving support or even rise to resource curse. If people expect these high democratization costs they may be more tolerant to autocratic regime.

All considerations above aim to explain why resource abundance increases stability of autocracy. The arguments are not completely convincing, however. We know that many autocrats are not able to support high institutional quality. If the quality is lower than a threshold level, the country experiences resource curse, and people consumption grows slowly. Corruption and bad governance may provoke people dissatisfaction and facilitate formation of opposition movements. Indeed, though most of resource abundant developing countries are non-democratic, not all of them were autocracies during all their history. In a number of such countries, there were attempts of radical changes to introduce modern democracy regimes based on broad suffrage rights. However, in almost all cases democracy was short lived and was soon replaced by a kind of the authoritarian regime. At the same time, resource richness does not seem to be a threat for democracy in more developed societies.

Thus there are two sides of the connection between resource abundance and the prevalence of autocratic governance: stability of autocracy and instability of democratic regimes. To our best knowledge, the second side was not studied systematically. The main goal of this paper is to cover this gap.

There are some evidences that, in less developed countries, democracy is often instable.

Carothers (2002) points out that of nearly 100 countries that are considered as newcomers to the democratic world from authoritarianism, only 18 (10 countries of Eastern Europe; Brazil, Chile, Mexico, Uruguay in Latin America; Taiwan, the Philippines and South Korea in East Asia; Ghana in Africa) "are clearly en route to becoming successful well-functioning democracies or at least have made some democratic progress and still 
enjoy a positive dynamics of democratization". A number of other papers differentiate between young and mature democratic regimes. Clague et al $(1996$, p.1) show that "the age of a democratic system is strongly correlated with property and contract rights." Akhmedov and Zhuravskaya (2004) demonstrate that political cycles are deeper and therefore more costly under immature democratic regimes.

If quick democratization occurs in an autocratic resource abundant country with weak institutions then, as was mentioned above, its institutions are deteriorating. This increase chances of recession due to resource curse that, in this case, works against new democratic regime. Therefore it is plausible that the new democracy is instable. We argue, however, that its instability is even more plausible in comparison with countries that have the same level of institutional quality and production. Specifically, we will show that the dominance of resource sector is an important factor that increases this potential instability.

Note that instability of democracy in resource-rich weak-institution countries results in people disappointment in democracy and therefore sharply weakening any democratic opposition to autocratic regime. This creates fifth, ideological channel through which autocracy is supported.

In this paper we analyze data on stability of democratic regimes in resource rich countries and suggest a model to explain why resource abundance may lead to instability of democracy in some countries (even if an incumbent does not pretend to autocratic power), but does not create any difficulties for a democratic system in other ones.

Everyone, who studies political regimes, faces a difficult methodological problem: the regimes have not generally accepted definitions. There are at least three possible approaches to differentiate between democracy and autocracy: structural (or institutional), behavioral, and intrinsic (or psychological) one. The structural approach underlines fundamental difference in institutions of decision making. Democratic decision making is based on elections, party systems and parliaments whereas autocracy uses organizational hierarchy where main decisions are made by a leader. However, democratic institutions are observed also in many countries where political regime is recognized as autocratic one. Though the institutions play more or less decorative role, they presence makes this criterion fuzzy enough. The second, behavior approach takes into account real changes of political power as a result of nation-wide elections. In accordance to this criterion, many countries (with dominant-party system) widely recognized as democratic ones would be 
classified as autocracies (for example, Sweden in 1940-1988, Japan in 1955-1993, Ireland in 1957-1973, Botswana in 1956-2006). The intrinsic approach stresses the difference in intrinsic goals of main political players under two regimes. A typical democratic politician is oriented towards interests of her group of voters whereas a dominated autocrat's goal is power itself. This approach is very stylized as well. We know that some autocrats defend interests of their referent groups whereas some democratic leaders like their voters much less than power. Wintrobe (2007) suggests a classification of autocrats: an autocrat can be a tinpot or a totalitarian. A tinpot is motivated by personal interests such as wealth, whereas a totalitarian is interested in power per ce or in some ideology. According to this classification, we consider the second type of autocrats.

Below we use all three approaches to describe democracy. An incumbent democratic Politician may be dismissed by elections, and there is non-zero probability of this event. Both players have the same policy instrument (tax rate of rent). The assumed structures of the utility functions give an advantage to the Autocrat since she may freely choose between populist and pro-oligarch policies dependently of the conditions. Therefore we assume also that voters are democracy disposed so that Politician has an advantage as well. Since we consider one period model, there is no need to describe authoritarian system in detail. Thus, we use the term "autocracy" in a very narrow sense. In fact we consider a political competition between two players with intrinsically different goals.

Our central idea is as follows. If a country is abundant by point resources, this creates a prerequisite for resource owners to have dominant economic power. If institutions are weak under democracy, the economic power may be converted into political one. Resource owners ("oligarchs") can thrust their preferred decisions on a parliament, bribing politicians. This creates a base for a potential Autocrat's strategy to get power using populist or pro-oligarch policies.

Rate of resource rent tax is considered as the only policy instrument in our simple model. The tax affects the income of a representative voter. Choosing a tax rate, Autocrat competes with conventional Politician (a representative political party) for the office.

We investigate how the probability of the democracy preservation is influenced by the fundamental asymmetry of a resource abundant economy; the asymmetry is measured by ratio of the resource rent and the income created in non-resource sectors. 
Our model demonstrates that, as a rule, the probability of the democracy preservation is a non-increasing function of resources. However, the exact outcome depends on the comparative efficiency of democratic governments (abilities to allocate tax revenues without big losses) and the expected Autocrat's efficiency (that the public assigns to the Autocrat). We show the existence of a threshold for propensity to corruption (a measure of the institutional quality) if expected Autocrat's efficiency is not higher than the efficiency of democratic governments. In this case the probability of the democracy preservation is decreasing in the amount of resources if the propensity is high and is independent of resources or even grows with the amount of resources if the propensity is low. If the Autocrat is expected to be more efficient, there is a threshold for resource amounts such that the Autocrat wins with probability 1 if the available resource amount exceeds the threshold level. It is shown also that Autocrat prefers to use two different types of policies depending on the qualities of governance More efficient Autocrat is inclined to follow populist high tax policy whereas lower Autocrat's efficiency results in pro-Oligarch low tax policy when the country is resource abundant.

Specifically, we consider a situation in which resource owners ("oligarchs") bribe politicians to induce them to vote for low taxation of resource sector. This, however, is assumed to decrease average income of citizens and creates a base for two types of Autocrat's policies mentioned above. The populist policy has a direct effect on the population choice. The impact mechanism of the pro-Oligarch policy is more subtle. Announcing low rent tax rate, Autocrat induces Oligarch to suggest larger bribe to Politician in exchange for a decrease of effective tax rate. If the derivative of the effective tax rate with respect to Autocrat announcement is larger than 1, it increases Autocrat's chances to be elected.

A combination of the probabilistic voting model and a principal-agent bribing model is used to describe the influence of the system institutional quality on the outcome of elections. Autocrat is considered as a principal of the second hierarchical level. This seems to be reasonable: she observes real behavior of other players and therefore has much more information about it than the other players have on her potential response function.

Our model is compatible with the fact that not only new democracies but also many autocracies turn out to be very corrupted (see Acemoglu, Robinson, Verdie (2003) for references, discussion and a theory). To some extent this fact may be reflected by our indicator of Autocrat's expected efficiency. However, our model is heavily based on two 
strong assumptions. First, we assume that Autocrat values power much higher than money. Second, her announcements are assumed to be credible at least partially so that she can influence expectations of other players . Both assumptions should be a subject of further research. Specifically, a multi-period model is required to make Autocrat's credibility endogenous.

\section{A Model}

The model describes an election system in a resource-abundant country with imperfect institutions. There are four actors in the model: the natural resource sector governed by a representative Oligarch, "public" (people who are not involved in resource extraction they form a handsome majority in the society), "a representative Politician" (political party representing this majority) and a potential Autocrat.

Production is not described. The resource rent (revenue net of production costs including minimum profit rate at which firms are willing to work) is $R$. The rent is taxed at rate $\tau \in[0,1]$, so that only $(1-\tau) R$ is earned by the resource sector ${ }^{1}$. Tax rate $\tau$ is considered as the only policy instrument in this simple model. Share $\xi \in[0,1]$ of the tax revenues is equally distributed among the public and the rest is dissipated .We assume here that the tax does not cause any distortion. Politician and Autocrat may have different values of $\xi$ s. These indicators may be considered as measures of governance quality of the political regimes.

Four participants play a one period game with complete information. Autocrat competes with the coalition of the incumbent Politician and Oligarch for the power. Both sides suggest their tax rates that define corresponding incomes of citizens. All citizens have equal incomes. However the income is only the first term of their utility function. The second one is stochastically distributed and reflects their preferences. Elections are described by a probabilistic voting model. Its outcome is a probability $p\left(\tau, \tau^{0}\right)$ of Politician's win as a function of two tax rates, where $\tau$ is chosen by Politician and $\tau^{0} \in[0,1]$ by Autocrat $^{2}$. This probability function is used by both Politician and Oligarch to calculate

\footnotetext{
${ }^{1}$ Note that only net profit is considered as the tax base in this model (so, the maximum level of $\tau$ is 1). The share of the tax in the revenues of resource-extracting firms is lower.

${ }^{2}$ Tax rate $\tau^{0}$ is only a declaration concerning future policy, not an actual choice by the Autocrat. The
} 
their expected incomes. Politician's utility function is supposed to be a weighted sum of her expected income and a bribe $B \geq 0$ paid by Oligarch. The income is connected with average income of population, so that it may serve as a measure of prestige as well. The weighting coefficient reflects institutional quality of the democratic system (another indicator is its governance quality mentioned above). Oligarch maximizes the sum of her expected after-tax income less the bribe.

We use principal - agent model as a very simple scheme of interaction between Oligarch and Politician. Oligarch is a principal. She maximizes her utility function under an incentive compatibility constraint. The constraint means that Politician may refuse to take bribes and get her most preferable parliament decision on the tax rate. Thus she agrees on another tax rate only if the bribe compensates her potential losses.

We assume that Autocrat is not interested in incomes at all. Thus, according to the classification suggested by Wintrobe (2007), we consider the case of pure totalitarian Autocrat whose ultimate goal is power. Therefore she chooses tax rate $\tau^{0}$ so as to minimize the probability $p\left(\tau, \tau^{0}\right)$ or, in other words, to maximize the probability of her win. As distinct from Politician, neither does Autocrat care about her personal gain, nor about social welfare (unless these objectives increase her power). This difference in goals is a very stylized attempt to distinguish between two types of political actors. We believe that this difference catches a characteristic feature of reality in the case of totalitarian rather than tinpot Autocrat.

Autocrat moves first in the game. Oligarch and Politician observe $\tau^{0}$ prior to their negotiation and believe that the tax rate will be $\tau^{0}$, if Autocrat wins.

Let us describe the model precisely. The governance quality of Politician is denoted as $\xi_{1}$ and that of Autocrat, as $\xi_{2}\left(\xi_{2}\right.$ may be lower or higher than $\left.\xi_{1}\right)$. Denote by $W$ the base income of the public (under no redistributive tax policy). Then after tax redistribution, the income will be $W+\xi_{1} \tau R$ under democracy and $W+\xi_{2} R$ under autocracy. Being elected Politician gets average citizen income times $\lambda>1$, a parameter measuring benefits of political power. If Autocrat wins, then Politician loses the benefits of his parliamentary position. So, we assume that the utility of Politician under no corruption denoted as $f\left(\tau, \tau^{0}\right)$ is given by

$$
f\left(\tau, \tau^{0}\right)=\lambda p\left(\tau, \tau^{0}\right)\left(W+\xi_{1} \tau R\right)+\left(1-p\left(\tau, \tau^{0}\right)\left(W+\xi_{2} \tau^{0} R\right) .\right.
$$

discussion on why this declaration is credible is given in the end of section 4 . 
The utility of Oligarch under no corruption denoted as $g\left(\tau, \tau^{0}\right)$ is equal to his expected after-tax profit:

$$
g\left(\tau, \tau^{0}\right)=p\left(\tau, \tau^{0}\right)(1-\tau) R+\left(1-p\left(\tau, \tau^{0}\right)\right)\left(1-\tau^{0}\right) R
$$

If there is some corruption in the democratic political system and the bribe paid by Oligarch to Politician is $B$, then the utilities of the parties (respectively, $F$ and $G$ ) are given by

$$
\begin{aligned}
& F\left(\tau, \tau^{0}, B\right)=f\left(\tau, \tau^{0}\right)+b \\
& G\left(\tau, \tau^{0}, B\right)=g\left(\tau, \tau^{0}\right)-B,
\end{aligned}
$$

where $b=\frac{B}{\gamma} ; \gamma>0$ is a parameter measuring costs of the corrupt behavior for the politicians. This parameter represents the level of institutional development of the democratic system and includes measures against corruption and the degree of benevolence of the politicians.

It would be relevant to assume that $\gamma>1$ (since transaction costs are positive). However, functions $f$ and $g$ can measure the respective benefits of Politician and Oligarch in different units. This can be so by many reasons: different number of politicians and oligarchs (note that both Politicians and Oligarch are representative agents), different size of their reference groups and so on. Additionally, Politician may exhibit low or high degree of benevolence (want only money or take care about citizens). All these possibilities can be captured by allowing $\gamma$ be any positive number, not necessarily greater than 1 . This will be assumed throughout the paper.

The size of bribe, $B$, is determined from the principal-agent relationship between Oligarch and Politician (Oligarch makes an offer, Politician can accept or reject). So, corrupted Politician must have the same utility as in the case of no corruption, whence

$$
b=b\left(\tau, \tau^{0}\right)=f\left(1, \tau^{0}\right)-f\left(\tau, \tau^{0}\right)
$$

and $B\left(\tau, \tau^{0}\right)=\gamma b\left(\tau, \tau^{0}\right)$.

The probability of sustaining democracy $p\left(\tau, \tau^{0}\right)$ is derived endogenously from the following probabilistic election model. Consider an arbitrary voter $i$. His utility of democracy is given by

$$
u_{1 i}=W+\xi_{1} \tau R+\left(\varepsilon_{i}-\delta\right) W
$$


and that of autocracy is given by

$$
u_{2 i}=W+\xi_{2} \tau^{0} R
$$

where $\varepsilon_{i}$ and $\delta$ are stochastic characteristics of political preferences: $\varepsilon_{i}$ is an "ideological bias" specific for each voter (measuring the extent to which he prefers democracy) and $\delta$ is a "popularity shock" characterizing the relative attractiveness of Autocrat in the population as a whole (apart from benefits from her expected policy). Denote by $\Psi(\varepsilon)$ and $\Phi(\delta)$ cumulative distribution functions for $\varepsilon$ and $\delta$, respectively. We assume that voter $i$ supports the autocrat, if $u_{2 i}>u_{1 i}$ and the autocrat wins, if he is supported by some share of the public, not less than $\mu(\mu \in[0,1])$.

Throughout the paper, the following example of $\Phi(\delta)$ will be used:

$$
\Phi(\delta)=e\left(\frac{1}{2}+h(\delta+\kappa)\right)
$$

where $h$ is a parameter measuring homogeneity of political preferences, $\kappa$ is a parameter of asymmetry (the higher is $\kappa$, the more preferred is democracy relative to autocracy for the society) and $e(\cdot)$ is a "crop function":

$$
e(x)=\min (\max (x, 0), 1)
$$

The cumulative function defined by (7) implies that the popularity shock $\delta$ is distributed uniformly between $-\frac{1}{2 h}-\kappa$ and $\frac{1}{2 h}-\kappa$.

\section{Tax Policy and Stability of Democracy}

The analysis of the model begins with deriving $p\left(\tau, \tau^{0}\right)$, the probability of sustaining democracy.

Proposition 1 Probability $p\left(\tau, \tau^{0}\right)$ is a non-decreasing function of $\tau$ given by

$$
p\left(\tau, \tau^{0}\right)=\Phi\left(K+\left(\xi_{1} \tau-\xi_{2} \tau^{0}\right) A\right),
$$

where $K=\Psi^{-1}(\mu)$ and $A=\frac{R}{W}$.

Proof. Voter $i$ supports the autocrat, if $u_{2 i}>u_{1 i}$, i. e., due to (5) and (6),

$$
\varepsilon_{i} \leq\left(\xi_{2} \tau^{0}-\xi_{1} \tau\right) A+\delta
$$


Autocrat will not win (and thus democracy will be retained), if the share of voters satisfying (10) does not exceed $\mu$, i. e.

$$
\Psi\left(\left(\xi_{2} \tau^{0}-\xi_{1} \tau\right) A+\delta\right) \leq \mu
$$

which is equivalent to

$$
\delta \leq K+\left(\xi_{1} \tau-\xi_{2} \tau^{0}\right) A
$$

The probability of holding inequality (12) is just $p\left(\tau, \tau^{0}\right)$ and is equal to the right-hand side of $(9)$.

The probability $p\left(\tau, \tau^{0}\right)$ does not depend on $R$ or $W$ separately but only on their ratio, $A$. This is true for all our further conclusions as well. From now on, we always assume that $W=1, R=A$. Note also that as far as we assume that the natural resource sector is dominant in the economy, $A$ cannot be very small.

Since the popularity shock $\delta$ is distributed uniformly in accordance with $(7), p\left(\tau, \tau^{0}\right)$ is a piecewise linear function of $\tau, \tau^{0}$ :

$$
p\left(\tau, \tau^{0}\right)=e\left(\left(\xi_{1} \tau-\xi_{2} \tau^{0}\right) h A+m\right)
$$

where

$$
m=\frac{1}{2}+h(K+\kappa)
$$

and $e(\cdot)$ is the crop function defined by (8). Note that $p\left(\tau, \tau^{0}\right)=0$, if $\tau \leq \underline{\tau}\left(\tau^{0}\right)$ and $p\left(\tau, \tau^{0}\right)=1$, if $\tau \geq \bar{\tau}\left(\tau^{0}\right)$, where

$$
\begin{aligned}
\underline{\tau}\left(\tau^{0}\right) & =\frac{\xi_{2} \tau^{0}-\frac{m}{h A}}{\xi_{1}} ; \\
\bar{\tau}\left(\tau^{0}\right) & =\frac{\xi_{2} \tau^{0}+\frac{1-m}{h A}}{\xi_{1}} .
\end{aligned}
$$

It is useful to have in mind interpretations of parameters $K, \kappa, h$ and $m$. The right-hand side of (10) may be interpreted as the Autocrat's general advantage. Then, in accordance to (10), voter $i$ supports the Autocrat if this advantage exceeds $i$ 's personal ideological disposition ("ideological bias") towards democracy. The Autocrat wins if her advantage is higher than critical Autocrat's general advantage level, $K$. Relative general disposition 
of the society toward Politician is measured by $\kappa$. The larger is $\kappa$, the more popular is the Politician. As for $h$, it represents the stability of political preferences exhibited by the public. Below we assume that $h$ is exogenously given, though it would be more realistic to consider $h$ as a function of players' strategies. General political preference parameter $\kappa$ will be considered as exogenous in the current section and endogenous (depending on the average corruption activity), in the next section.

In this section, we assume the following relationship between parameters:

$$
\begin{array}{ll}
\frac{1}{2}<m<1 & \text { (democracy is (in average) preferred to autocracy } \\
& \text { and popularity shocks are significant enough); } \\
\lambda>\max \left(\frac{\xi_{2}}{\xi_{1}}, 1\right) & \begin{array}{l}
\text { (benefits of political career are large enough, } \\
\text { so the politicians will not want to give up their position). }
\end{array}
\end{array}
$$

Since $m$ is assumed to be higher than $\frac{1}{2}$, the society considered in the model, is, ceteris paribus, democracy oriented (see (13) under $\xi_{1}=\xi_{2}$ ). This bias is assumed to be not too large, so that Autocrat has some chances to win under equal efficiencies of the players. Note that due to this democracy bias, more stable political preferences (represented by higher $h$ ) imply higher probability of democracy surviving.

The analysis of the game between Autocrat, Oligarch and Politician proceeds with deriving Oligarch's equilibrium strategy $\tau\left(\tau^{0}\right)$ (his optimal choice of the tax rate, given the Autocrat's tax rate).

Proposition 2 Oligarch's equilibrium strategy $\tau\left(\tau^{0}\right)$ and the corresponding probability of sustaining democracy $p\left(\tau\left(\tau^{0}\right), \tau^{0}\right)$ are determined as follows:

(a) if $\gamma<\bar{\gamma}$, then

$$
\begin{aligned}
& \tau\left(\tau^{0}\right)= \begin{cases}e\left(\underline{\tau}\left(\tau^{0}\right)\right), \quad \text { if } \tau^{0} \leq \underline{\tau}^{0}(A, \gamma) ; \\
C \tau^{0}+\frac{\tilde{D}}{A}, \quad \text { if } \underline{\tau}^{0}(A, \gamma)<\tau^{0}<\bar{\tau}^{0}(A, \gamma) ; \\
e\left(\bar{\tau}\left(\tau^{0}\right)\right), \quad \text { if } \tau^{0} \geq \bar{\tau}^{0}(A, \gamma) ;\end{cases} \\
& p\left(\tau\left(\tau^{0}\right), \tau^{0}\right)= \begin{cases}e\left(m-\xi_{2} \tau^{0} h A\right), & \text { if } \tau^{0} \leq \underline{\tau}^{0}(A, \gamma) ; \\
\xi_{1} h\left(\tau^{0} \tilde{C} A+D\right), & \text { if } \underline{\tau}^{0}(A, \gamma)<\tau^{0}<\bar{\tau}^{0}(A, \gamma) ; \\
e\left(m+\left(\xi_{1}-\xi_{2} \tau^{0}\right) h A\right), & \text { if } \tau^{0} \geq \bar{\tau}^{0}(A, \gamma) ;\end{cases}
\end{aligned}
$$


(b) if $\gamma \geq \bar{\gamma}$, then $\tau\left(\tau^{0}\right)=1$ and $p\left(\tau\left(\tau^{0}\right), \tau^{0}\right)=e\left(m+\left(\xi_{1}-\xi_{2} \tau^{0}\right) h A\right)$.

Here

$$
\begin{aligned}
& C=\frac{\tilde{\Delta}}{2 \Delta}+\frac{\xi_{2}}{2 \xi_{1}}>0 ; \\
& \tilde{C}=\frac{\tilde{\Delta}}{2 \Delta}-\frac{\xi_{2}}{2 \xi_{1}} ; \\
& D=\frac{\gamma(\lambda-1)}{2 \Delta}+\frac{m}{2 \xi_{1} h}>0 ; \\
& \tilde{D}=\frac{\gamma(\lambda-1)}{2 \Delta}-\frac{m}{2 \xi_{1} h} \text {; } \\
& \underline{\tau}^{0}(A, \gamma)=\max \left(-\frac{\tilde{D}}{C A},-\frac{D}{\tilde{C} A}\right) \\
& \bar{\tau}^{0}(A, \gamma)=\min \left(\frac{1-\frac{\tilde{D}}{A}}{C}, \frac{\frac{1}{\xi_{1} h}-D}{\tilde{C} A}\right) ; \\
& \Delta=1-\lambda \gamma \xi_{1}>0 \\
& \tilde{\Delta}=1-\gamma \xi_{2}>0 \text {; } \\
& \bar{\gamma}=\frac{1}{\lambda \xi_{1}}
\end{aligned}
$$

(All the notations and inequalities in (19)-(21) are relevant and valid for $\gamma<\bar{\gamma}$ ).

Proof. If $\tau^{0}$ is set by Autocrat, then tax rate $\tau$ chosen by Oligarch is a solution to the following bargaining maximization problem ${ }^{3}$ :

$$
V\left(\tau, \tau^{0}\right)=\gamma f\left(\tau, \tau^{0}\right)+g\left(\tau, \tau^{0}\right) \rightarrow \max _{\tau}
$$

s. t.

$$
0 \leq \tau \leq 1
$$

Case (a). If $\gamma<\bar{\gamma}$, then the objective function in (23) is strictly concave in $\tau$ for $\tau$ satisfying inequality

$$
e\left(\underline{\tau}\left(\tau^{0}\right)\right) \leq \tau \leq e\left(\bar{\tau}\left(\tau^{0}\right)\right) .
$$

\footnotetext{
${ }^{3}$ This maximization problem is actually relevant for any bargaining solution, not only for the principal - agent relationship between Oligarch and Politician.
} 
Moreover, in this case constraint (24) may be replaced with (25). Indeed, $V\left(\tau, \tau^{0}\right)$ does not depend on $\tau$ for $\tau \in\left[0, e\left(\underline{\tau}\left(\tau^{0}\right)\right)\right]$ and is linear in $\tau$ for $\tau \in\left[e\left(\bar{\tau}\left(\tau^{0}\right)\right), 1\right]$ (these statements are relevant, when the corresponding intervals have positive length). If $\gamma<\bar{\gamma}$ and $\bar{\tau}\left(\tau^{0}\right)<1$, then

$$
V\left(\bar{\tau}\left(\tau^{0}\right), \tau^{0}\right)-V\left(1, \tau^{0}\right)=\left(1-\bar{\tau}\left(\tau^{0}\right)\right)\left(1-\gamma \lambda \xi_{1}\right) A>0
$$

Thus, at least one of the solutions to (23)-(24) is always subject to (25).

Under our assumptions, problem (23) subject to (25) is a problem of maximizing a strictly concave function over an interval. Formula (17) is just the first-order condition to this maximization problem and (18) immediately follows from (13) and (17).

Case (b): see in Appendix.

Note that functions $\underline{\tau}^{0}(A, \gamma)$ and $\bar{\tau}^{0}(A, \gamma)$ are defined as solutions of the following equations

$$
C \underline{\tau}^{0}(A, \gamma)+\tilde{D} / A=e\left(\underline{\tau}\left(\tau^{0}\right)\right) ; C \bar{\tau}^{0}(A, \gamma)+\tilde{D} / A=e\left(\bar{\tau}\left(\tau^{0}\right)\right) .
$$

Now let us study the behavior of the equilibrium tax rates $\tau^{0}$ and $\tau=\tau\left(\tau^{0}\right)$ set, respectively, by Autocrat and corrupt Politician and the corresponding probability of sustaining democracy $p\left(\tau\left(\tau^{0}\right)\right), \tau^{0}$ under different levels of resource abundance and institutional development.

Autocrat's maximization problem is

$$
p\left(\tau\left(\tau^{0}\right), \tau^{0}\right) \rightarrow \min _{\tau^{0}}
$$

s. t.

$$
\begin{aligned}
& \tau\left(\tau^{0}\right) \text { is the solution to }(23)-(24) \text { for given } \tau^{0} \\
& 0 \leq \tau^{0} \leq 1
\end{aligned}
$$

The solution to problems (27)-(28) may have different properties, depending on the relationship between the parameters of the model. The relation between the governance quality rates $\xi_{1}$ and $\xi_{2}$ is crucial here.

The variety of cases takes the simplest form when the governance qualities of Politician and Autocrat are the same. 
Proposition 3 If autocracy is as much efficient as democracy $\left(\xi_{1}=\xi_{2}\right)$, then one of the following three cases takes place ${ }^{4}$ :

(a) if institutions are weak and there are not much natural resources ( $\gamma<\gamma_{D}, A<$ $A_{1}(\gamma)$ ), then there will be populist Autocrat's policy $\left(\tau^{0}=1\right)$ and pro-Oligarch Politician's policy $(\tau=0)$; the probability of sustaining democracy will be decreasing in $A$ and will not depend on $\gamma$;

(b) if institutions are weak and there are much natural resources $\left(\gamma<\gamma_{D}, A>A_{1}(\gamma)\right)$, then Autocrat will follow partially pro-Oligarch policy $\left(\tau^{0}=\underline{\tau}^{0}(A, \gamma)\right.$, decreasing in $A$, increasing in $\gamma)$, Politician will follow pro-Oligarch policy $(\tau=0), p$ will be independent of $A$ and increasing in $\gamma$;

(c) if institutions are strong $\left(\gamma>\gamma_{D}\right)$, then Autocrat will follow populist policy $\left(\tau^{0}=1\right)$, there will be no corruption $(\tau=1)$, with $p$ being constant $(p=m)$.

Here

$$
\begin{aligned}
& \gamma_{D}=\frac{1}{\xi_{1}\left(\frac{(\lambda-1) h}{m}+\lambda\right)} \quad\left(\tilde{D}<0 \text { for } \gamma<\gamma_{D} \text { and } \tilde{D}>0 \text { for } \gamma>\gamma_{D}\right) \\
& \left.A_{1}(\gamma)=\max \left(-\frac{\tilde{D}}{C}, 0\right) \quad \text { decreasing in } \gamma \text { for } \gamma<\gamma_{D}\right) ; \\
& \underline{\tau}^{0}(A, \gamma) \text { is defined in (20). }
\end{aligned}
$$

Proof. The proof is based on formulas for $p\left(\tau\left(\tau^{0}\right), \tau^{0}\right)$ obtained in Proposition 2 (see formula (18)).

Case (a). In this case, $\tau^{0}(A, \gamma)>1$, so $\tau\left(\tau^{0}\right)=0$ for any $\tau^{0}$. As follows from (18), $p\left(\tau\left(\tau^{0}\right), \tau^{0}\right)$ is decreasing in $\tau^{0}$ in this case, so the Autocrat will choose $\tau^{0}=1$.

Case (b). In this case, due to the restrictions on $A, 0<\underline{\tau}^{0}(A, \gamma)<1$, Since $\tilde{C}>0$ for $\xi_{1}=\xi_{2}$, there can be three segments within [0,1], with $p\left(\tau\left(\tau^{0}\right), \tau^{0}\right)$, respectively, decreasing, increasing and decreasing in $\tau^{0}$ (the third segment may be absent). Such function may have two local minimums, $\tau^{0}=\underline{\tau}^{0}(A, \gamma)$ and $\tau^{0}=1$. In the case considered here, the first of them is global (see Figure 1(a)).

Case (c). In this case, either $p\left(\tau\left(\tau^{0}\right), \tau^{0}\right)$ is decreasing in $\tau^{0}$, or, as in case (c), there is a segment where it is increasing but the global minimum is anyway at $\tau^{0}=1$ (see

\footnotetext{
${ }^{4}$ From now on, combinations of parameters which are boundary for some cases are not considered.
} 


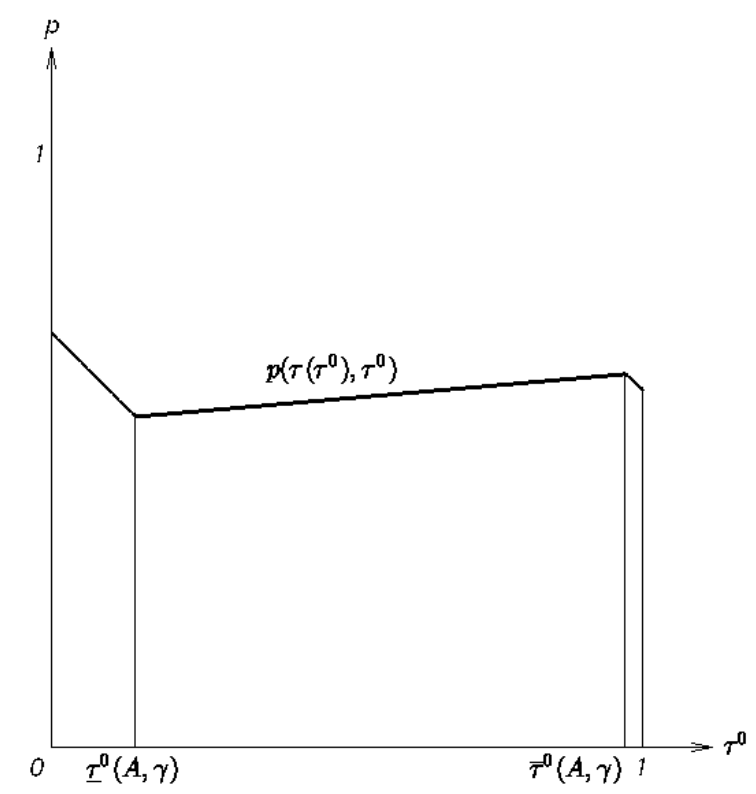

(a) $\tau^{0}=\underline{\tau}^{0}(A, \gamma)$ in equilibrium

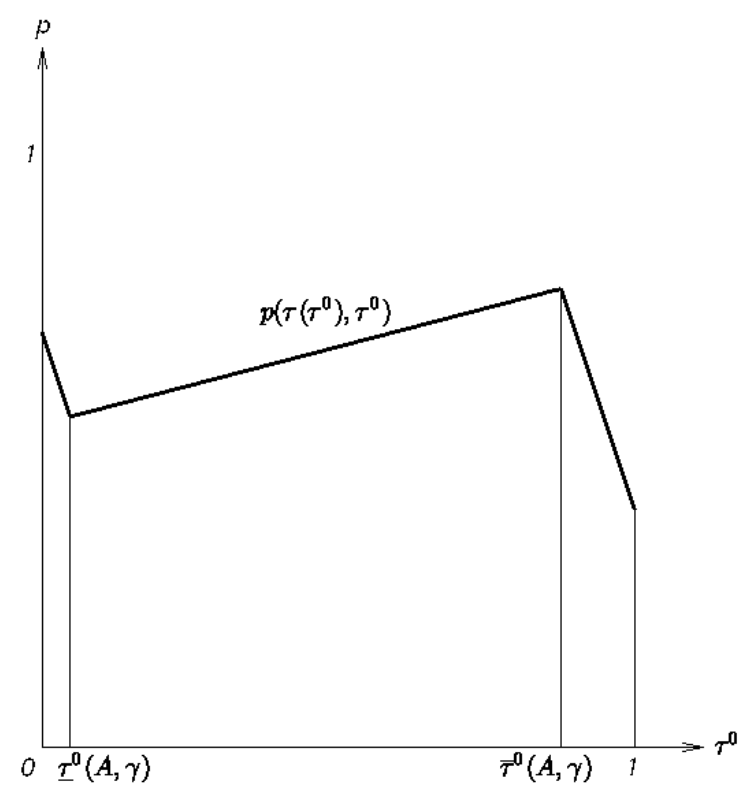

(b) $\tau^{0}=1$ in equilibrium

Figure 1: Graph of $p\left(\tau\left(\tau^{0}\right), \tau^{0}\right)$ for positive $\tilde{C}$.

Figure 1(b)). Note that such solution of Autocrat's optimization problem implies $p=m=$ const for $\xi_{1}=\xi_{2}$.

Note that in any case, $0<p<1$ in equilibrium.

The variety of cases in Proposition 3 is depicted in Figure 2 (c). Thick curves separate plain $(A, \gamma)$ into three areas corresponding to three cases (a), (b) and (c). Thin curves are level lines for function $p(A, \gamma)$ depicting the impact of resource abundance and institutions on the stability of democracy.

As Figure 2 (c) shows, if $\xi_{1}=\xi_{2}$, then for each level of institutional quality, $\gamma$, one can find a threshold, $A_{1}(\gamma)$, such that the probability of sustaining democracy, $p$, is decreasing in $A$ if $A<A_{1}(\gamma)$, but does not depend on $A$ if $A>A_{1}(\gamma)$. The better are institutions, the lower is the threshold, i. e. the narrower is the interval where political regimes are dependent of resources.

If $A$ is fixed, then the probability of sustaining democracy, $p$, grows with $\gamma$ if $A$ is large enough $\left(A>A_{1}(\gamma)\right.$ and $\gamma$ is not too high $\left(\gamma<\gamma_{D}\right)$. Under comparatively small resource endowments, institutional quality does not influence political regimes. The same is true if the quality is higher than the threshold level $\gamma_{D}$. In this case, $p=m$. Thus, the probability of democracy surviving depends only on the disposition to democracy represented by $K$, 


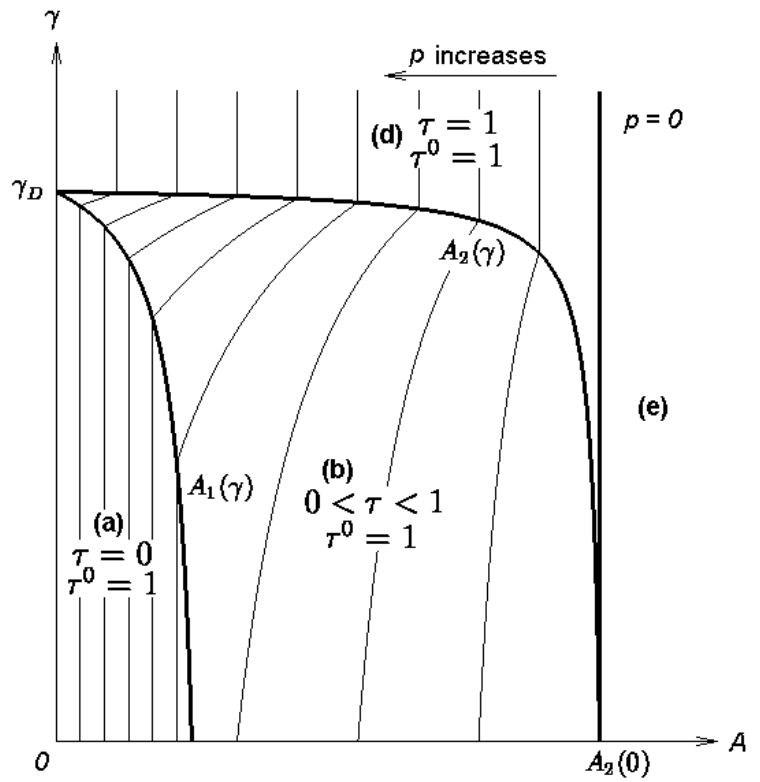

(a) $\xi_{1}<\xi_{2}, \gamma_{C}>\gamma_{D}($ Proposition 4$)$

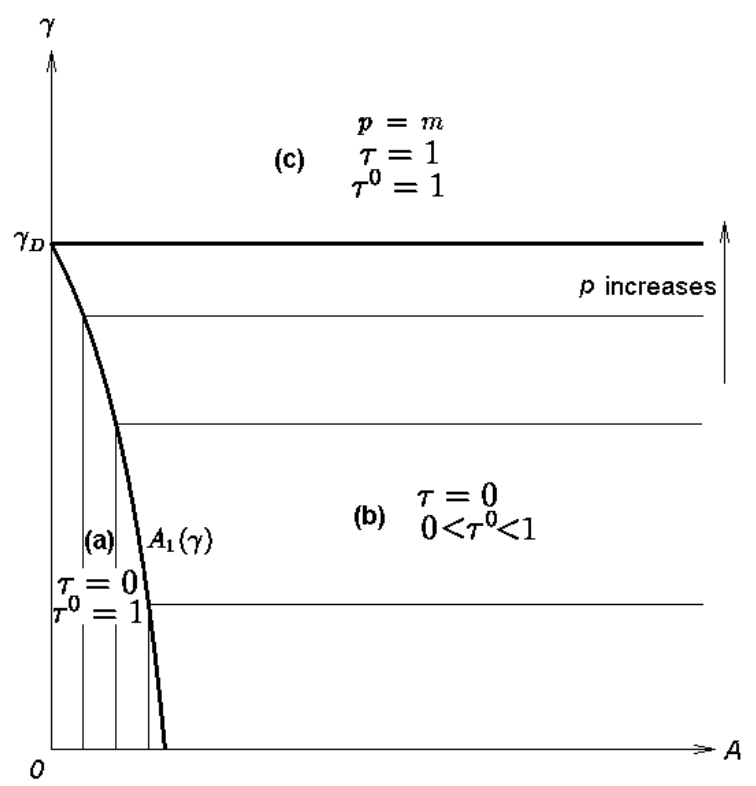

(c) $\xi_{1}=\xi_{2}$ (Proposition 3)

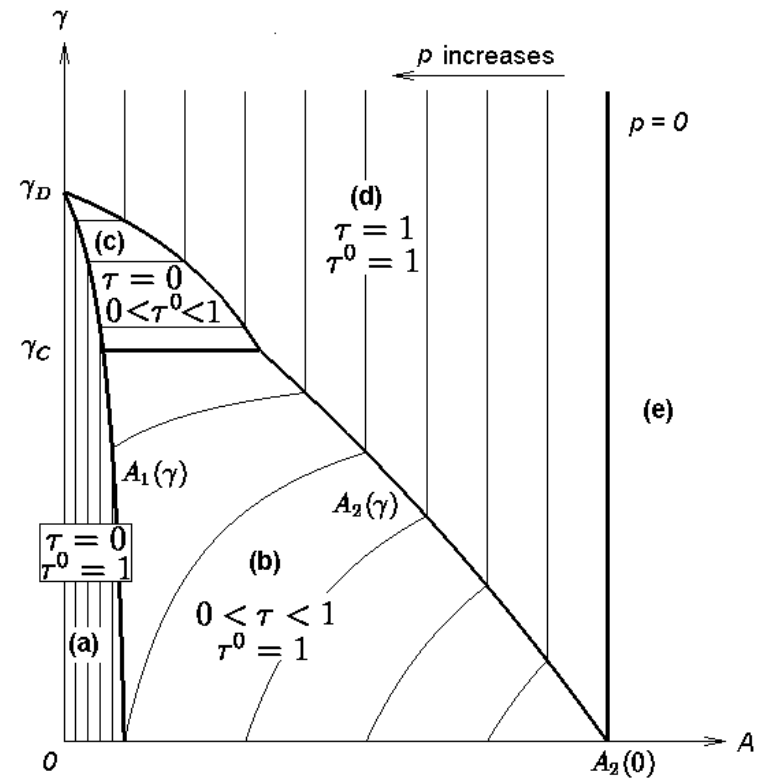

(b) $\xi_{1}<\xi_{2}, \gamma_{C}<\gamma_{D}$ (Proposition 4)

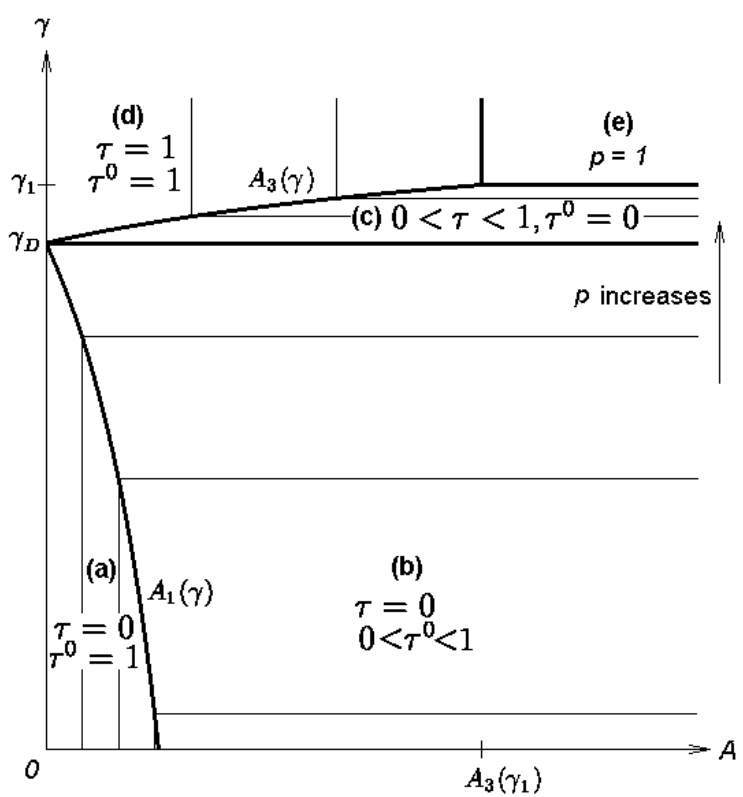

(d) $\xi_{1}>\xi_{2}$ (Proposition 5)

Figure 2: Probability of retaining democracy depending on $A$ and $\gamma$. 
$\kappa$ and $h$.

The choice of strategies in equilibrium described by Proposition 3 can be explained by two reasons. Firstly, the impact of resource rent taxation on the probability of sustaining democracy and on the payoffs of Politician and Oligarch positively depends on the size of the rent (see (1), (2) and (13)). Secondly, the impact of the bribe negatively depends on $\gamma$.

In case (a), the rent is small and the propensity to corruption is high, so bribing Politician is an efficient strategy: a small bribe can stimulate Politician to set the minimal tax rate even if Autocrat promises to follow a populist strategy. As the rent goes up (case (b), lowering the tax rate gets more expensive for the Politician because the probability of losing his political power gets more sensitive to the tax rate. Thus, higher bribe is needed to lower the tax rate. Autocrat is interested in low taxes under the democratic system because the extant of economic inequality positively affects the probability of his winning. To encourage political corruption, Autocrat promises lower tax rate thus partially cooperating with Oligarch.

If the rent is constant (and not very high) and the institutional quality increases, then bribing gets more efficient which firstly leads to the same effect (from case (a) to (b)). However, when the quality reaches threshold level $\gamma_{D}$, case (b) is replaced with (c), where there is no bribe and the probability of sustaining democracy is maximal and depends only on the societal and cultural characteristics (represented by $\kappa$ and $h$ ) and the democratic institutions represented by $K$.

Now let us look what will change if democracy and autocracy exhibit different governance quality. We start with examining the case where autocracy is more efficient than democracy.

Proposition 4 Let $\xi_{1}<\xi_{2}$. Then one of the following five cases takes place:

(a) $\gamma$ and $A$ are low $\left(\gamma<\gamma_{D}, A<A_{1}(\gamma)\right) \Longrightarrow$ populist Autocrat's policy $\left(\tau^{0}=1\right)$, pro-Oligarch Politician's policy $(\tau=0), p$ is decreasing in $A$ and does not depend on $\gamma$;

(b) $\gamma$ is low, $A$ is intermediate $\left(\gamma<\min \left(\gamma_{C}, \gamma_{D}\right), A_{1}(\gamma)<A<A_{2}(\gamma)\right) \quad \Longrightarrow$ populist Autocrat's policy $\left(\tau^{0}=1\right)$, moderate corruption $(0<\tau<1), \tau$ is increasing in $A$ and $\gamma$, $p$ is decreasing in $A$ and increasing in $\gamma$; 
(c) $\gamma$ and $A$ are intermediate $\left(\gamma_{C}<\gamma<\gamma_{D}, A_{1}(\gamma)<A<A_{2}(\gamma)\right) \Longrightarrow$ partially pro-Oligarch Autocrat's policy $\left(\tau^{0}=\underline{\tau}^{0}(A, \gamma)\right.$, decreasing in A, increasing in $\left.\gamma\right)$, proOligarch Politician's policy $(\tau=0), p$ does not depend on $A$ and is increasing in $\gamma$ (this case is relevant when $\gamma_{C}<\gamma_{D}$ );

(d) $A$ is intermediate $\left(A_{2}(\gamma)<A<A_{2}(0)\right) \Longrightarrow$ populist Autocrat's policy $\left(\tau^{0}=1\right)$, no corruption $(\tau=1), p$ is decreasing in $A$ and does not depend on $\gamma$;

(e) $A$ is high $\left(A>A_{2}(0)\right) \Longrightarrow$ Autocrat has a (populist) strategy yielding her $100 \%$ probability of winning ( $\tau^{0}$ is sufficiently high, $\left.p=0\right)$.

Here

$$
\begin{gathered}
\gamma_{C}=\frac{\frac{1}{\xi_{1}}-\frac{1}{\xi_{2}}}{\lambda-1} \quad\left(\tilde{C}<0 \text { for } \gamma<\gamma_{C} \text { and } \tilde{C}>0 \text { for } \gamma>\gamma_{C}\right) \\
A_{2}(\gamma)= \begin{cases}-\frac{\xi_{2} \tilde{D}}{\left(\xi_{2}-\xi_{1}\right) C}, & \text { if } \left.\gamma_{C}<\gamma<\gamma_{D} \text { (relevant when } \gamma_{C}<\gamma_{D}\right) \\
-\frac{\tilde{D}}{C-1}, & \text { if } \gamma \leq \min \left(\gamma_{C}, \gamma_{D}\right) ; \\
0, & \text { if } \gamma \geq \max \left(\gamma_{C}, \gamma_{D}\right)\end{cases} \\
\left(A_{2}(\gamma) \text { is decreasing in } \gamma \text { for } \gamma<\gamma_{D} ; \quad A_{2}(0)=\frac{m}{\left(\xi_{2}-\xi_{1}\right) h}\right)
\end{gathered}
$$

Proof. The proof is based on formulas for $p\left(\tau\left(\tau^{0}\right), \tau^{0}\right)$ obtained in Proposition 2 (see formula (18)).

Case (a). Analogous to case (a) in Proposition 3.

Case (b). Since $\tilde{C}<0$ in this case, then, as follows from (18), $p\left(\tau\left(\tau^{0}\right), \tau^{0}\right)$ is decreasing in $\tau^{0}$ for any $\tau^{0}$, so $\tau^{0}=1$. The restrictions on $A$ yield $\underline{\tau}^{0}(A, \gamma)<1<\bar{\tau}^{0}(A, \gamma)$ which means that $\tau=\tau(1)$ is between 0 and 1 .

Case (c). In this case, $\tilde{C}<0$ and the proof is analogous to that of case (b) in Proposition 3.

Case (d). Analogous to case (c) in Proposition 3, with the only difference being negative dependence of $p$ on $A$.

Case (e). In this case, $\underline{\tau}\left(\tau^{0}\right)>1$ for sufficiently high $\tau^{0}$ (for example, for $\tau^{0}=1$ ), so the Oligarch and Politician have no collusion strategy yielding them a positive probability of sustaining the democratic system for these $\tau^{0}$. 
Note that in cases $(\mathrm{a})-(\mathrm{d}), 0<p<1$ in equilibrium.

The variety of cases in Proposition 4 is depicted in Figure 2 (a), (b).

Note that under very large resource rent and not very good institutions (case (e)), the efficiency gap between autocracy and democracy plays a crucial role and the Autocrat wins with $100 \%$ probability, regardless of the strategies of Politician and Oligarch.

Now let us study the case where democracy is more efficient than autocracy.

Proposition 5 Let $\xi_{1}>\xi_{2}$. Then one of the following five cases takes place:

(a) $\gamma$ and $A$ are low $\left(\gamma<\gamma_{D}, A<A_{1}(\gamma)\right) \Longrightarrow$ populist Autocrat's policy $\left(\tau^{0}=1\right)$, pro-Oligarch Politician's policy $(\tau=0), p$ is decreasing in $A$ and does not depend on $\gamma$;

(b) $\gamma$ is low, $A$ is high $\left(\gamma<\gamma_{D}, A>A_{1}(\gamma)\right) \Longrightarrow$ partially pro-Oligarch Autocrat's policy $\left(\tau^{0}=\underline{\tau}^{0}(A, \gamma)\right.$, decreasing in A, increasing in $\left.\gamma\right)$, pro-Oligarch Politician's policy $(\tau=0), p$ does not depend on $A$ and is increasing in $\gamma$;

(c) $\gamma$ is intermediate, $A$ is high $\left(\gamma_{D}<\gamma<\gamma_{1}, A>A_{3}(\gamma)\right) \Longrightarrow$ pro-Oligarch Autocrat's policy $\left(\tau^{0}=0\right)$, moderate corruption $(0<\tau<1), \tau$ is decreasing in $A$ and increasing in $\gamma, p$ does not depend on $A$ and is increasing in $\gamma$;

(d) $\gamma$ is high, $A$ is low $\left(\gamma>\gamma_{D}, A<A_{3}\left(\gamma_{1}\right), A<A_{3}(\gamma)\right.$ for $\left.\gamma<\gamma_{1}\right) \Longrightarrow$ populist Autocrat's policy $\left(\tau^{0}=1\right)$, no corruption $(\tau=1), p$ is increasing in $A$ and does not depend on $\gamma$;

(e) $\gamma$ and $A$ are high $\left(\gamma>\gamma_{1}, A>A_{3}\left(\gamma_{1}\right)\right) \Longrightarrow$ The optimal Oligarch's strategy $\left(\tau=\bar{\tau}\left(\tau^{0}\right)\right.$ for $\gamma<\bar{\gamma}$ and $\tau=1$ for $\left.\gamma>\bar{\gamma}\right)$ yields $100 \%$ probability of sustaining democracy for any $\tau^{0}$ set by Autocrat, so $p=1$.

Here

$$
\begin{aligned}
& \gamma_{1}=\frac{1}{\xi_{1}\left(\frac{(\lambda-1) h}{2-m}+\lambda\right)}>\gamma_{D} \\
& A_{3}(\gamma)=\max \left(\frac{\xi_{1}}{\xi_{1}-\xi_{2}} \tilde{D}, 0\right) \\
& \quad\left(\text { increasing in } \gamma \text { for } \gamma_{D}<\gamma<\bar{\gamma} ; A_{3}\left(\gamma_{1}\right)=\frac{1-m}{\left(\xi_{1}-\xi_{2}\right) h}\right) .
\end{aligned}
$$

Proof. Cases (a), (b) and (d) are analogous to, respectively, cases (a), (b) and (c) in Proposition 3 (or (a), (c) and (d) in Proposition 4), with the only difference being 
the positive dependence $p(A)$ in case (d) for $\xi_{1}>\xi_{2}$. If $\tilde{D}>0$ (cases (c), (d) and (e)), then $\underline{\tau}^{0}(A, \gamma)<0$, so the left segment in Figure1 is absent and local minimums in cases (c) and (d) can be reached at $\tau^{0}=0$ and $\tau^{0}=1$. In case $c$, the first of them is global and in case $(\mathrm{d})$, the second of them is global (the first one may not exist for high $\gamma$ ). In case (e), $\bar{\tau}\left(\tau^{0}\right) \leq 1$ for all $\tau^{0} \in[0,1]$ and $\frac{\partial}{\partial \tau} V\left(\bar{\tau}\left(\tau^{0}\right), \tau^{0}\right)>0$, so the solution to problem (23)-(24) is $\tau\left(\tau^{0}\right)=\bar{\tau}\left(\tau^{0}\right)$ for $\gamma<\bar{\gamma}$ and $\tau\left(\tau^{0}\right)=1$ for $\gamma>\bar{\gamma}$ (see Proposition 2). Thus, $p\left(\tau\left(\tau^{0}\right), \tau^{0}\right)=1$ regardless of the autocrat's strategy in case $(\mathrm{e})$.

The variety of cases in Proposition 5 is depicted in Figure 2(d).

This Figure leads to the following conclusions. First, as a rule, the probability of the democracy preservation is a non-increasing function of resources. The only exception is case (d) of Proposition 5 when democracy is more efficient and propensity to corruption is low. In this case, Politician's populist policy gives her the greater advantage the larger is available resource amount

Second, there exists a threshold for propensity to corruption if expected Autocrat's efficiency is not higher than the efficiency of the democratic government. In this case the probability of the democracy preservation is decreasing in the amount of resources if the propensity is higher than the threshold and is independent of resources or even grows with the amount of resources if the propensity is lower.

Third, if the Autocrat is expected to be more efficient, there is a threshold for resource amounts such that the Autocrat wins for sure if the available resource amount exceeds the threshold level.

Fours, the Autocrat prefers to use two different types of policies depending on the qualities of governance More efficient Autocrat is inclined to follow populist high tax policy whereas lower Autocrat's efficiency results in pro-Oligarch low tax policy when the country is resource abundant. This last policy induces Oligarch to bribe Politician in exchange for a tax decrease that weakens Politician's chances to be reelected. 


\section{Corruption Externality: More Instability of Democ- racy}

It was shown in the previous section that if democracy is as much efficient as autocracy (or more efficient than autocracy), the probability of sustaining democracy is not affected by resource abundance and may be sufficiently high even if the institutional quality is relatively low and the available resource amount is large (see Propositions 3(b) and 5(b)). This result seems to be not very consistent with the reality: observation of empirical data suggests that countries with large amount of natural resources are more often ruled by autocratic power than those with medium or small amount.

To adopt this observation, let us modify the model as follows. Suppose that the corruption activity exerts externality: $b$, the sum of bribes appropriated by politicians ${ }^{5}$, negatively affects the attractiveness of democracy represented by $m$ (recall that $m$ is determined by (14) and depends on the distribution parameters of the popularity shock and ideological bias). Thus, $m$ is not an exogenous constant now, it is a function: $m=m(b)$, where, according to (4),

$$
b=b\left(\tau, \tau^{0}\right)=\frac{B\left(\tau, \tau^{0}\right)}{\gamma}=f\left(1, \tau^{0}\right)-f\left(\tau, \tau^{0}\right) .
$$

For simplicity, let us restrict our analysis to the equal efficiency case $\left(\xi_{1}=\xi_{2}=\xi\right)$ and consider the following simple linear function $m(b)$ :

$$
m(b)=m_{0}-\alpha b
$$

where $\frac{1}{2}<m_{0}<1$ and $\alpha>0$. If $b$ is large, then $m(b)$ may be negative. It means that the initial ideological advantage of democracy disappears due to high corruption level. As above, we assume $\lambda>1$.

Under the new setting, the behavior of our players is not changed. Making their decisions, they determine corruption level $b$ considering $m$ as a fixed quantity. However, this quantity has to be equal to $m(b)$ in equilibrium

The equilibrium value of $b$ for given $\tau$ and $\tau_{0}$ is determined by (34) considered as an

\footnotetext{
${ }^{5}$ It is more appropriate here to consider a number of identical politicians not taking into account the externality they exert, rather than a single Politician who may care about it.
} 
equation with respect to $b$ :

$$
\begin{aligned}
& b=f\left(1, \tau^{0}\right)-f\left(\tau, \tau^{0}\right)= \\
& =\left(p\left(1, \tau^{0}\right)-p\left(\tau, \tau^{0}\right)\right)\left(\xi\left(\lambda-\tau^{0}\right) A+\lambda-1\right)+\xi \lambda(1-\tau) p\left(\tau, \tau^{0}\right) A,
\end{aligned}
$$

where $p\left(\tau, \tau^{0}\right)$ is the probability of sustaining democracy (see (13)):

$$
\left.\left.p\left(\tau, \tau^{0}\right)=e\left(\left(\tau-\tau^{0}\right) \xi h A+m(b)\right)\right)=e\left(\left(\tau-\tau^{0}\right) \xi h A+m_{0}-\alpha b\right)\right) .
$$

If $0<p\left(\tau, \tau^{0}\right)<1$ and $0<p\left(1, \tau^{0}\right)<1$, then the solution to (35) is given by

$$
b=\frac{\left(\lambda\left(\tau-\tau^{0}\right)+\lambda-\tau^{0}\right) \xi h A+\lambda m_{0}+(\lambda-1) h}{\alpha \lambda+\frac{1}{\xi(1-\tau) A}} .
$$

As follows from (38), larger resource rent will bring about more corruption activity, provided that both $\tau$ and $\tau^{0}$ remain unchanged. Note also that we cannot expect any more that $\kappa$ or even $m$ be positive: they are linearly decreasing in $A$ and may get negative for large $A$.

It turns out that in the presence of the corruption externality, the probability of sustaining democracy will no longer stabilize under low institutional quality, as $A$ grows large. It will fall down to zero instead, as the following proposition shows.

Proposition 6 Let $\xi_{1}=\xi_{2}$ and the corruption externality is present with $m(b)$ given by (35). Then one of the following five cases takes place:

(a) $\gamma$ and $A$ are low $\left(\gamma<\tilde{\gamma}, A<A_{4}(\gamma)\right) \Longrightarrow$ populist Autocrat's policy $\left(\tau^{0}=1\right)$, pro-Oligarch Politician's policy $(\tau=0), p$ is decreasing in $A$ and does not depend on $\gamma$;

(b) $\gamma$ is low, $A$ is intermediate $\left(\gamma<\tilde{\gamma}, A_{4}(\gamma)<A<A_{5}(\gamma)\right) \Longrightarrow$ partially proOligarch Autocrat's policy $\left(\tau^{0}=\underline{\tau}^{0}(A, \gamma)\right.$, decreasing in A, increasing in $\left.\gamma\right)$, pro-Oligarch Politician's policy $(\tau=0), p$ is decreasing in $A$ and increasing in $\gamma$;

(c) $\gamma$ is intermediate, $A$ is high enough $\left(A>A_{5}(\gamma), \gamma_{0}(A, 0)<\gamma<\gamma_{0}\left(A, m_{0}\right)\right) \Longrightarrow$ pro-Oligarch Autocrat's policy $\left(\tau^{0}=0\right)$, moderate corruption $(0<\tau<1), \tau$ is decreasing in $A$ and increasing in $\gamma, p$ is decreasing in $A$ and increasing in $\gamma$;

(d) $\gamma$ is high $\left(\gamma>\gamma_{0}\left(A, m_{0}\right)\right) \Longrightarrow$ Autocrat follows populist policy $\left(\tau^{0}=1\right)$, no corruption $(\tau=1), p=m_{0}=$ const. 
(e) A is high, $\gamma$ is low $\left(\gamma<\gamma_{0}(A, 0)\right) \Longrightarrow$ Autocrat has a (pro-Oligarch) strategy yielding her $100 \%$ probability of winning ( $\tau^{0}$ is sufficiently low, $p=0$ ).

Here

$$
\tilde{\gamma}=\frac{m_{0}}{\xi\left(\lambda m_{0}+(\lambda-1) h\right)}
$$

$A_{4}(\gamma)$ is the solution to $A=A_{1}(\gamma)$ with respect to $A$ (or zero if there is no one), provided that $m$ is the solution to $m=m_{0}-\alpha b(0,1)\left(A_{4}(\gamma)\right.$ is decreasing in $\gamma$ for $\left.\gamma<\tilde{\gamma}\right)$;

$A_{5}(\gamma)$ is the solution to $\gamma=\gamma_{D}$ with respect to $A$ (or zero if there is no one), provided that $m$ is the solution to $m=m_{0}-\alpha b\left(0, \underline{\tau}^{0}(A, \gamma)\right)\left(A_{5}(\gamma)\right.$ is decreasing in $\gamma$ for $\left.\gamma<\tilde{\gamma}\right)$;

$\gamma_{0}(A, q)$ is the solution to $p(\tau(0), 0)=q$ with respect to $\gamma$, provided that $p(\tau(0), 0)$ is determined by (18) (with $\tau^{0}=0$ ) and $m$ is the solution to $m=m_{0}-\alpha b(\tau(0), 0) ; \gamma_{0}(A, q)$ is increasing in $A$ and $q$ and $\lim _{A \rightarrow \infty} \gamma_{0}(A, q)=\bar{\gamma}=\frac{1}{\xi \lambda}$ for any $q \in\left[0, m_{0}\right]$.

Proof. Suppose that $0<p\left(\tau, \tau^{0}\right)<1$ and $0<p\left(1, \tau^{0}\right)<1$. Let us calculate $A_{4}(\gamma)$, $A_{5}(\gamma)$ and $\gamma_{0}(A, q)$ in this case. It is easy to show that

$$
\begin{aligned}
& A_{4}(\gamma) \text { is the solution to } \gamma=\frac{\frac{m_{0}}{\xi}-(\alpha \xi(2 \lambda-1) A+2+\alpha(\lambda-1)) h A}{\lambda m_{0}+(\lambda-1) h-\left(\alpha \lambda^{2} \xi A+\lambda+1\right) \xi h A} ; \\
& A_{5}(\gamma) \text { is the solution to } \gamma=\frac{\frac{m_{0}}{\xi}-(\lambda \xi A+\lambda-1) \alpha h A}{\lambda m_{0}+(\lambda-1) h-\xi^{2} \alpha \lambda^{2} h A^{2}} ; \\
& \gamma_{0}(A, q)=\frac{\alpha Q(\lambda Q+(\lambda-1) h)+h\left(2 q-m_{0}\right)}{\xi\left(\alpha \lambda Q(\lambda Q+2(\lambda-1) h)+h^{2}(\lambda-1)(\alpha(\lambda-1)+1)+\lambda h\left(2 q-m_{0}\right)\right)},
\end{aligned}
$$

where $Q=q+\xi h A$. It can be checked that these functions have properties declared in the proposition. Note also that $A_{4}(\tilde{\gamma})=A_{5}(\tilde{\gamma})=0, \gamma_{0}\left(A_{5}(0), 0\right)=0$ and $\gamma_{0}\left(0, m_{0}\right)=\tilde{\gamma}$.

Case (a). If $A<A_{4}(\gamma)$, then case (a) of Proposition 3 takes place.

Case (b). If $A_{4}(\gamma)<A<A_{5}(\gamma)$, then case (b) of Proposition 3 takes place.

Case (c). In this case, $\underline{\tau}^{0}(A, \gamma)<0$ and the proof is analogous to that of case (c) in Proposition 5. Note that $p$ is the solution to $\gamma_{0}(A, p)=\gamma$ in this case (thus, the graphs of $\gamma_{0}(A, q)$ for different $q$ are just level lines for $p$ in plain $(A, \gamma)$ in this case (see Figure 3)).

Case (d). This condition on parameters leads to case (c) of Proposition 3. 


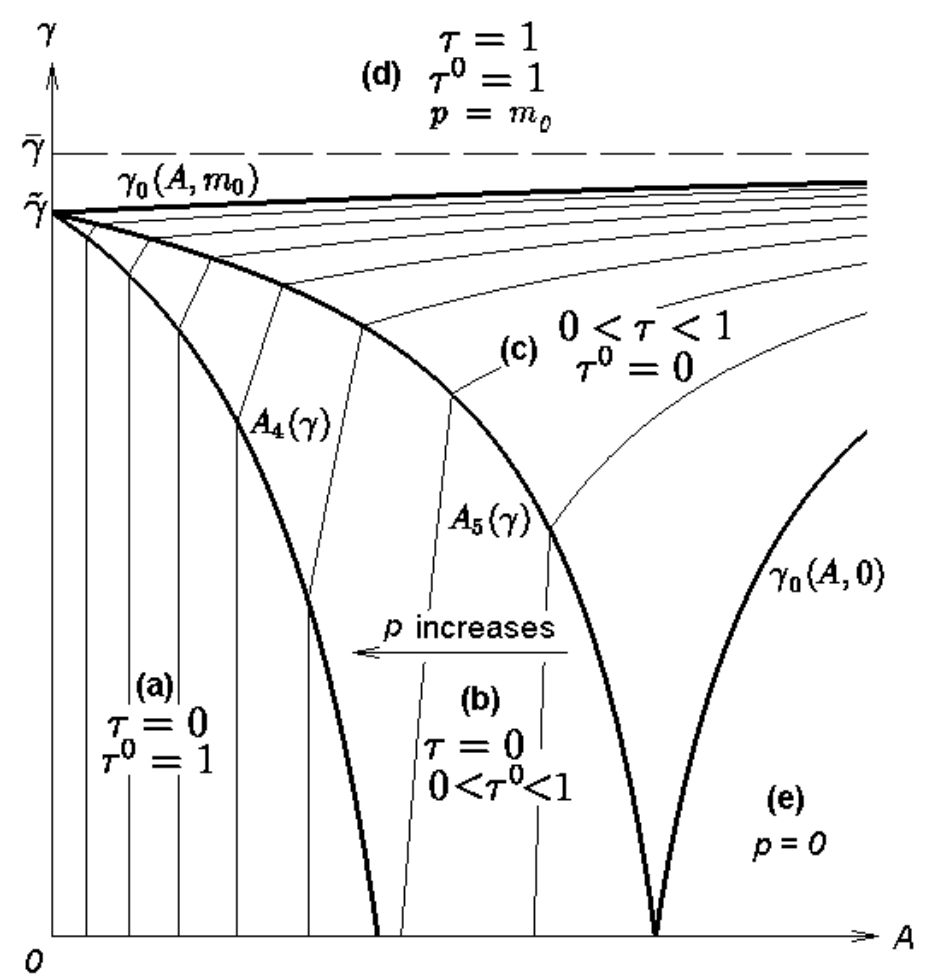

Figure 3: Probability of retaining democracy: $\xi_{1}=\xi_{2}$, corruption externality.

Case (e). In this case, $\underline{\tau}\left(\tau^{0}\right)>1$ for sufficiently low $\tau^{0}$ (for example, for $\tau^{0}=0$ ), so the autocrat wins for sure.

The above considerations are based on the assumption that $0<p\left(1, \tau^{0}\right)<1$. If (e) is not the case, then $p\left(1, \tau^{0}\right) \geq p\left(\tau, \tau^{0}\right)>0$, so only one inequality, namely, $p\left(1, \tau^{0}\right)<1$ is to be checked. It is easy to show that this inequality is violated only for sufficiently high $A$. In particular, if $\alpha \lambda>h$, then the inequality can be violated only in cases (c) and (e). In case $(\mathrm{c})$, function $\gamma_{0}(A, q)$ is given by

$$
\gamma_{0}(A, q)=\frac{\left(2 q-m_{0}\right) h+\alpha \lambda\left(\xi h A+q^{2}\right)+\alpha(\lambda-1)(1-q) h}{\xi\left(\left(2 q-m_{0}\right) \lambda h+(\lambda-1) h(h+\alpha \lambda)+\alpha \lambda^{2}\left(\xi h A+q^{2}\right)\right)} .
$$

It is easy to check by examining (39) and (40) that in any case, $\gamma_{0}(A, q)$ is increasing in $A$ and $q$ and $\lim _{A \rightarrow \infty} \gamma_{0}(A, q)=\bar{\gamma}$ for any $q$.

The statements about dependencies of $\tau$ and $p$ on $A$ and $\gamma$ can be proved by direct computation of the corresponding partial derivatives.

Regions in plain $(A, \gamma)$ corresponding to cases in Proposition 6 are depicted in Figure 3.

It follows from Proposition 6 and Figure 3 that the probability of the democracy preservation is decreasing in the amount of resources if the propensity to corruption $1 / \gamma$ 
is higher than the threshold $1 / \Gamma(A)$ (where $\Gamma(A)=\gamma_{0}\left(A, m_{0}\right)$ ) and is independent of resources if the propensity is lower. The higher is $A$ the better institutional quality is required to reach maximal probability. It also follows that, when $A$ grows and the quality is not high, the Autocrat changes her announced policy from populist to pro-oligarch one (not only due to increasing inequality which has been discussed above but also due to higher bribes which positively affect the probability of his winning). This policy brings Autocrat to the power if the system turns out to be in the area (e), where the resource rent is large and institutions are weak, because the impact of bribes on the public preference of autocracy over democracy gets essential.

Let us conclude the analysis of the theoretical model with the following important remark. It has been implicitly assumed so far that the public, Politician and Oligarch trust that Autocrat will follow her declared policy. Why are there reasons to trust?

Suppose that Autocrat changes the legislative base so that the election process is cancelled or gets no more than a formal procedure, so Autocrat can lose her power only after a revolution (as in Acemoglu et al (2003) or Wantchekon (1999)). Suppose also that Oligarch has resources that are not controlled by Autocrat and can help to organize a revolution. The more natural resources, the more credible this threat. Thus, after the Autocrat wins, she has to keep the balance between Oligarch and public. She can ignore Oligarch if the rent is small but has to defer more and more as the rent gets larger. Hence, have a reason to believe that actual future policy of Autocrat is somewhat consistent with her declaration (at least, the actual tax rate positively depends on the declared one).

\section{$5 \quad$ Stylized Facts And Empirical Findings}

Despite the widely held believes that the world is becoming freer and more democratic, there are in fact not so many countries that became democratic in the last three decades and managed to stay democratic thereafter. Consider the dynamics of the political rights index - measure of democracy compiled by Freedom House - in 1972-2002. It ranges from 7 (complete authoritarianism) to 1 (complete democracy) and measures the freedom of elections, manifestations, mass media, political parties, etc. During the third and forth wave of democratization, i.e. during the three decades, from 1972 to 2002, about 40 countries managed to move from authoritarianism to democracy and to stay that way 
(political right index decreased to 1-2 by 2002): 4 countries in Western Europe (Cyprus, Greece, Portugal, Spain), 12 countries in Eastern Europe (new entrants to the EU in 2005 and in 2007), 10 countries in Latin America, 7 in Africa and 6 in Asia and Oceania.

Over three dozen of new democracies in three decades may sound like a lot, but in fact there were more countries - full 100 - that moved to democracy during these three decades, but experienced at least some return to authoritarianism by the end of the period. Among these three dozen countries there were only two major fuel exporters - Bolivia and Mexico.

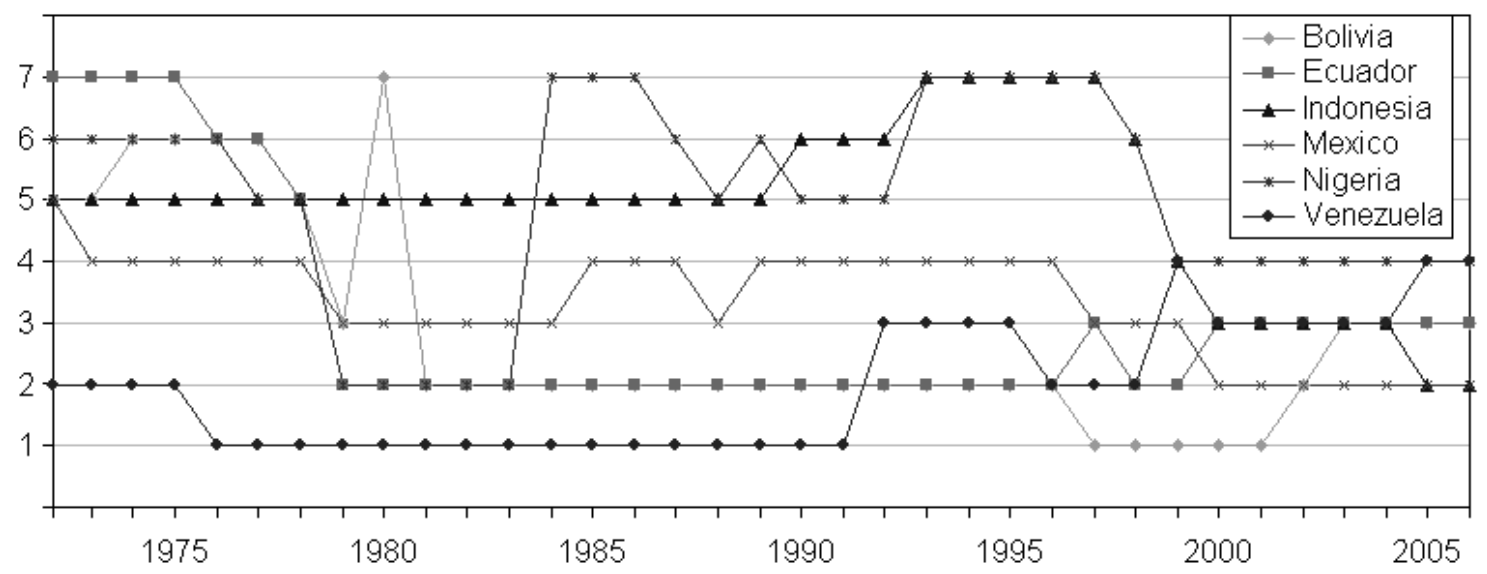

Figure 4: Democracy in Bolivia, Ecuador, Indonesia, Mexico, Venezuela, Nigeria

Even if we accept a looser criteria for democracy (a political rights index of 1 to 3 by the end of the period, in 2002, instead of 1 to 2) and draw a line at this level, the number of new democracies will increase to 54 as compared to about the same number of countries that may be called "unsuccessful democratizers", i.e. that tried to democratize, but ended up in authoritarianism by 2002. As the table below suggest, all countries in the world (on which statistics is available) can be divided into 4 roughly equal groups: (1) stable democracies - countries where the index of political rights was in between 1 and 3 for the whole period of 1972-2002, (2) stable autocracies - countries, where political rights index remained within the range of 4 to 7 for the whole 1972-2002 period; (3) new democracies - countries that were authoritarian before political right index within 4 to 7 ), but achieved democracy (political rights index from 1 to 3) by 2002; (4) unstable demo-autocracies - countries that were once democratic, but ended up in 2002 within the authoritarian range of political rights index (4 to 7 ). 
Table 1. Typology of democratic trajectories in 1972-2002.

\begin{tabular}{|c|c|c|}
\hline Countries & $\begin{array}{l}\text { Democratic in } 2002 \text { (Political rights index } \\
\text { equal to } 1,2 \text { or } 3 \text { ) }\end{array}$ & $\begin{array}{l}\text { Non-democratic in } 2002 \text { (political } \\
\text { right index is equal to } 4,5,6 \text { or } 7 \text { ) }\end{array}$ \\
\hline $\begin{array}{l}\text { Political rights } \\
\text { index remained } \\
\text { stable (within } \\
1-3 \text { for } \\
\text { democracies } \\
\text { and within } 4-7 \\
\text { for autocracies) } \\
\text { for the whole } \\
\text { period of } 1972- \\
2002\end{array}$ & $\begin{array}{l}\text { STABLE DEMOCRACIES } \\
\text { Western countries (except Cypnus, } \\
\text { Greece, Portugal, Spain) Bahamas, } \\
\text { Barbados, Belize, Botswana, Costa Rica, } \\
\text { India, Israel, Jamaica, Japan, Mauritius, } \\
\text { Papua New Guinea, Samoa, Sri Lanka, St. } \\
\text { Lucia, St. Kits and Nevis, St. Lucia, St. } \\
\text { Vincent and Grenadine, Trinidad and } \\
\text { Tobago, Vanuatu }\end{array}$ & $\begin{array}{l}\text { STABLE AUTOCRACIES Angola, } \\
\text { Azerbaijan, Bahrain, Bhutan, Bosnia, } \\
\text { Brunei, Bunundi, Cambodia, } \\
\text { Cameroon, Chad, China, Congo, Dem. } \\
\text { Rep., Cote D'Ivoire, Cuba, Egypt, } \\
\text { Equatorial Guinea, Ethiopia, Fiji, } \\
\text { Gabon, Guinea, Haiti, Iran, Iraq, } \\
\text { Kazakhstan, Kenya, Korea, Dem. } \\
\text { Rep., Kuwait, Kyrgyz Rep., Lao PDR, } \\
\text { Liberia, Libya, Mauritania, Myanmar, } \\
\text { Oman, Qatar, Rwanda, Saudi Arabia, } \\
\text { Singapore, Somalia, Sudan, } \\
\text { Swaziland, Syria, Tanzania, Togo, } \\
\text { Tunisia, Uganda, UAE, Uzbekistan, } \\
\text { Vietnam, Yemen } \\
\text { Overall: } 50 \text { countries }\end{array}$ \\
\hline $\begin{array}{l}\text { Political rights } \\
\text { index did not } \\
\text { remain stable } \\
\text { (within } 1-3 \text { for } \\
\text { democracies } \\
\text { and within } 4-7 \\
\text { for autocracies) } \\
\text { for the whole } \\
\text { period of } 1972- \\
2002\end{array}$ & $\begin{array}{l}\text { NEW DEMOCRACIES } \\
12 \text { new EE members of the EU + Albania, } \\
\text { Bangladesh, Benin, Bolivia, Brazil, Cape } \\
\text { Verde, Chile, Croatia, Cypnus, Dominican } \\
\text { Rep., El Salvador, Ecuador, Ghana, } \\
\text { Grenada, Greece, Guatemala, Guyana, } \\
\text { Honduras, Indonesia, Korea, Rep., } \\
\text { Madagascar, Mali, Mexico, Moldova, } \\
\text { Mongolia, Mozambique, Namibia, Nepal, } \\
\text { Nicaragua, Panama, Penu, Philippines, } \\
\text { Portugal, Senegal, Seychelles, South } \\
\text { Africa, Spain, Surinam, Thailand, } \\
\text { Unuguay, Yugoslavia, Venezuela } \\
\text { Overall: } 54 \text { countries }\end{array}$ & $\begin{array}{l}\text { UNSTABLE DEMO- } \\
\text { AUTOCRACIES } \\
\text { All other countries - about } 50 \text { - that } \\
\text { had an index of political rights from } 4 \\
\text { to } 7 \text { by } 2002 \text {, but at one point in } 1972- \\
2002 \text { were democratic (with the index } \\
\text { of } 1 \text { to } 3 \text { ), and later moved away from } \\
\text { democracy. } \\
\text { Example: Russia that had an index of } \\
3 \text { in the early } 1990 \text { s and } 5 \text { in } 2002 \\
\text { Overall: about } 50 \text { countries }\end{array}$ \\
\hline
\end{tabular}

It should be also taken into account that some of the "successful democratizers" became democratic quite recently and have yet to prove their success. Venezuela, for instance, classified as the "successful democratizer" by 2002, moved under Chavez to the political rights index of 4 in 2005-2006, whereas Thailand had a coup d'etat in 2006. In the following table, the group of new democracies ("successful democratizers") shown in the left lower quadrant of the preceding table is subdivided into four sub-groups using two criteria: the volatility of the index of political rights and the number of years before 2002, in which the index stayed within the 1 to 3 range.

It turns out that out of 52 countries classified previously as "new democracies", only 24 can be considered relatively stable, i.e. they stayed democratic for at least 8 years before 
Table 2. Typology of democratic trajectories in 1972-2002 for 52 new democracies (in parentheses - PPP GDP per capita in 1995 as a \% of the US level).

\begin{tabular}{|c|c|c|}
\hline Countries & $\begin{array}{l}\text { Democratic in 1994-2002 (Political rights } \\
\text { index equal to } 1,2 \text { or } 3 \text { ) }\end{array}$ & $\begin{array}{l}\text { Non-democratic in 1994- } 2002 \\
\text { (political right index at least } \\
\text { once was equal to } 4,5,6 \text { or } 7 \text { ) }\end{array}$ \\
\hline $\begin{array}{l}\text { Political rights } \\
\text { index never } \\
\text { returned to } \\
\text { authoritarian } \\
\text { values ( } 4 \text { to } 7 \text { ) } \\
\text { after it first fell } \\
\text { below } 4 \text { in the } \\
\text { period of } 1972 \text { - } \\
2002\end{array}$ & $\begin{array}{l}\text { NO AUTHORITARIAN REVERSALS, } \\
\text { OVER } 8 \text { YEARS OF DEMOCRACY } \\
\text { RECENTLY } \\
\text { New EE members of the EU with the } \\
\text { exception of Romania (9 countries: 18- } \\
\text { 47), Benin (3), Brazil (24), Cape Verde } \\
\text { (14), Ecuador (11), Greece (47), Honduras } \\
\text { (9), Korea, Rep. (49), Madagascar (3), } \\
\text { Mali (2), Mongolia (5), Namibia (19), } \\
\text { Panama (18), Philippines (13), Portugal } \\
\text { (49), Spain (55) } \\
\text { Overall: } 24 \text { countries (18) }\end{array}$ & $\begin{array}{l}\text { NO AUTHORITARIAN } \\
\text { REVERSALS, BUT LESS } \\
\text { THAN } 8 \text { YEARS OF } \\
\text { DEMOCRACY RECENTLY } \\
\text { Indonesia (10), Mexico (26), } \\
\text { Moldova (9), Mozambique (2), } \\
\text { Romania (23), South Africa (31), } \\
\text { Yugoslavia } \\
\text { Overall: } 7 \text { countries (17) }\end{array}$ \\
\hline $\begin{array}{l}\text { Political rights } \\
\text { index at least } \\
\text { once returned } \\
\text { to authoritarian } \\
\text { values ( } 4 \text { to } 7 \text { ) } \\
\text { after it first fell } \\
\text { below } 4 \text { in the } \\
\text { period of } 1972- \\
2002\end{array}$ & $\begin{array}{l}\text { AUTHORITARIAN REVERSALS IN } \\
\text { THE PAST, BUT OVER } 8 \text { YEARS OF } \\
\text { DEMOCRACY RECENTLY } \\
\text { Bangladesh (5), Bolivia (8), Chile (27), } \\
\text { Cyprus (60), El Salvador (14), Grenada } \\
\text { (19), Guyana (12), Nepal (4), Seychelles, } \\
\text { Suriname (7), Thailand (27)*, Uruguay } \\
\text { (28) } \\
\text { Overall: } 12 \text { countries (19) }\end{array}$ & $\begin{array}{l}\text { AUTHORITARIAN } \\
\text { REVERSALS IN THE PAST } \\
\text { AND LESS THAN } 8 \text { YEARS } \\
\text { OF DEMOCRACY } \\
\text { RECENTLY } \\
\text { Albania (10), Croatia (21), } \\
\text { Dominican Republic (15), Ghana } \\
\text { (6), Guatemala (12), Nicaragua } \\
\text { (8), Peru (16), Senegal (5), } \\
\text { Venezuela (21) } \\
\text { Overall: } 9 \text { countries (12) }\end{array}$ \\
\hline
\end{tabular}

* Thailand was democratic by 2002, but had a coup d'etat in 2006 .

2002 and never experienced any reversals in the democratization process in 1972-2002. Other countries were either very recent newcomers to the democratic club (less than 8 years of non-stop democracy by 2002), or experienced authoritarian reversals in 1972 2002 , or both. It is interesting to note that the average GDP per capita in these four groups of new democracies was roughly the same - 17-19\% of the US level in 1995, with the exception of the most unstable group in the right lower quadrant of the table - recent newcomers to the democratic club with the history of authoritarian reversals in the past.

All in all, it appears that what may be called a successful democratization is quite a rare case in the world in recent 30 years. Out of over 52 countries that democratized in 1972-2002 only 24 so far have managed to avoid the return to authoritarianism during these three decades and to stay democratic for at least 8 years by 2002 . Recall, that here 
we consider democratic countries that had the index of political rights within the range of 1 to 3 . If stricter criteria are applied ( 1 to 2 ), the number of successful democracies will be reduced to less than 20. Carothers (2002), as was mentioned already, counts only 18 countries that "have made some democratic progress and still enjoy a positive dynamics of democratization".

Virtually all fuel exporting countries are not democratic. In fact, there were only three democracies in the club in 2002 (Bolivia, Mexico, Norway) and Bolivia left the club in 2003-06. Even accepting the loose criterion for new democracies index of political rights of 3 and less), we find only 4 more fuel exporters in this group - Ecuador, Indonesia, Seychelles Venezuela - out of 25 (besides, Venezuela left the democratic club in 2006). And, as Figure 4 suggests, the stability of the democratic regime in these new democracies leaves a lot to be desired.

As Table 3 shows, out of 26 countries of the world, in which net fuel export exceeded $20 \%$ of the total export in 1960-99, only 3 countries were democratic by 2002 - Bolivia, Mexico and Norway. In all three countries, though, net fuel export did not exceed $22 \%$, so if the dividing line for defining fuel exporters is drawn at this level, there would be no democratic countries at all. The average political rights index for the 1972-2002 was above 3.0 for all countries except for 3 (Norway, Trinidad and Tobago, and Venezuela). Moreover, in 14 cases the index of political rights increased, i.e. the trend was towards authoritarianism, not towards democracy; in one case there was no trend at all (Norway), in two cases there was no data, and only in 9 cases there was a weak tendency towards democratization.

We use the following notations for the reported below cross country regressions that demonstrate the negative impact of resource abundance on the stability of democracy:

$D$ - average level of democracy in 1972-75, equals to the Freedom House index of political rights, ranging from 1 to 7 for every year; the absolute level shows the degree of authoritarianism, so, lower values mean more democracy (http://www.freedomhouse.org/ratings/index.htm),

$\Delta$ - democratization in 1973/75-1999/2002, equals to the change in democratization levels for the whole period and calibrated so as to make the indicator always positive and showing the increase in democratization, not in the authoritarianism: 
Table 3. Political rights index in fuel exporting countries (net fuel exports $>20 \%$ of total exports in 1960-99).

\begin{tabular}{|l|l|l|l|l|}
\hline Country & $\begin{array}{l}\text { Net } \\
\text { exports } \begin{array}{r}\text { fuel } \\
\text { in } \\
\mathbf{1 9 6 0 - 9 9} \text { as a \% } \\
\text { of total export }\end{array}\end{array}$ & $\begin{array}{l}\text { Political } \\
\text { rights } \\
\text { index } \\
\mathbf{2 0 0 2}\end{array}$ & $\begin{array}{l}\text { Average } \\
\text { inolitical } \\
\text { rights index } \\
\text { in 1972-2002 }\end{array}$ & $\begin{array}{l}\text { Trend in political } \\
\text { rights index in 1972- } \\
\mathbf{2 0 0 2} \text { coefficient } \\
\text { from regression } \boldsymbol{a x}+\boldsymbol{b} \text { ) }\end{array}$ \\
\hline Algeria & 86 & 6 & 6.0 & -0.004 \\
\hline Angola & 39 & 6 & 6.6 & \\
\hline Bahrain & 37 & 6 & 5.8 & 0.045 \\
\hline Bolivia & $\mathbf{2 0}$ & $\mathbf{1}$ & $\mathbf{3 . 0}$ & -0.18 \\
\hline Brunei & 97 & 7 & 6.3 & $\mathbf{0 . 0 4 4}$ \\
\hline Congo, Rep. & 45 & 5 & 6.0 & -0.041 \\
\hline Ecuador & 34 & 3 & 3.1 & -0.145 \\
\hline Egypt & 27 & 6 & 5.4 & 0.021 \\
\hline Gabon & 55 & 5 & 5.5 & -0.054 \\
\hline Indonesia & 40 & 3 & 5.3 & 0.018 \\
\hline Iran & 91 & 6 & 5.7 & 0.025 \\
\hline Iraq & 77 & 7 & 6.9 & 0.009 \\
\hline Kuwait & 67 & 4 & 5.0 & 0.0009 \\
\hline Libya & 97 & 7 & 6.6 & 0.017 \\
\hline Mexico & $\mathbf{2 0}$ & $\mathbf{2}$ & $\mathbf{3 . 6}$ & $\mathbf{- 0 . 0 3 4}$ \\
\hline Nigeria & 73 & 4 & 5.2 & 0.031 \\
\hline Norway & $\mathbf{2 2}$ & $\mathbf{1}$ & $\mathbf{1}$ & $\mathbf{0}$ \\
\hline Oman & 69 & 6 & 6.1 & -0.023 \\
\hline Qatar & 93 & 6 & 5.9 & 0.057 \\
\hline Russia & 39 & 5 & 5.3 & -0.125 \\
\hline Saudi Arabia & 95 & 7 & 6.4 & 0.049 \\
\hline Seychelles & 36 & 3 & 4.8 & \\
\hline Syria & 34 & 7 & 6.3 & 0.055 \\
\hline Trinidad and Tobago & 45 & 3 & 1.4 & -0.026 \\
\hline UAE & 58 & 6 & 5.6 & 0.022 \\
\hline Venezuela & 86 & 3 & 1.7 & 0.057 \\
\hline & & & & \\
\hline
\end{tabular}


$\Delta=4-\left(D_{99-02}-D_{73-75}\right)$,

DEMvol - standard deviation of the index of political rights in 1972-2002,

AUTlast_min - the index of political rights in 2002 divided by it's minimum value in the period 1972-2002. It is equal to 1 in about 100 cases, indicating that the country did not step back from the democracy track. In other cases (also about 100) it is greater than 1, showing the magnitude of the drift in the direction of authoritarianism by 2002 as compared to the most democratic year of the whole period,

$Y-$ PPP GDP per capita in 1975,

POP - population of a country in 1999, million people, measure of a country size,

IM fuel - net fuel imports as a \% of total imports in 1960-99,

IC - average 1984-90 investment climate index from the International Country Risk Guide: it ranges from 0 to 100\%, higher values mean better climate (World Bank),

$I C_{2000}-2000$ Investment Climate index from the International Country Risk Guide (World Bank, 2001),

CPIchange - increase in Corruption Perception Index from 1980-85 to 2002-03 (Transparency International, 53 countries). It shows the increase in the "cleanness" of the society and is another measure of institutional quality,

Rev - average share of central government revenues in GDP in 1971-75, \%,

Def - average share of defense spending in 1980-99, \% of GDP.

It is easy to show that democratization depends positively on net fuel imports, i.e. negatively on fuel export:

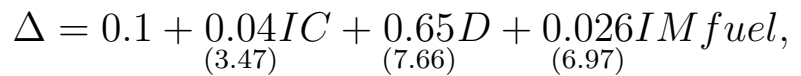

Adj R-squared $=0.43$, Number of obs. $=118$, Significance $-0.1 \%$.

where $\Delta$ - democratization in 1972-2002, IC - average 1984-90 investment climate index, $D$ - average level of democracy in 1972-75, I M fuel - net fuel imports as a \% of total imports in 1960-99.

Replacing investment climate index, $I C$, with PPP GDP per capita in $1975, Y$, yields 
basically the same results:

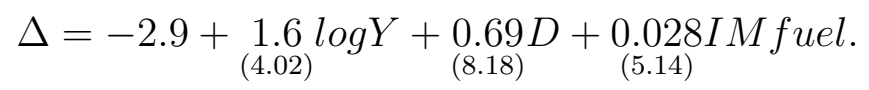

Adj R-squared $=0.45$, Number of obs. $=105$, Significance $-0.1 \%$.

It turns out that the increase in the democracy index (democratization) was less pronounced in countries with large fuel export, controlling for the initial level of democracy and for the initial (1975) GDP per capita or the quality of institutions in 1984-90.

Similar results can be obtained to explain the volatility of democracy (index of political rights):

$$
D E M v o l=0.9-\underset{(-2.31)}{0.009 I C}+\underset{(4.04)}{0.13 D}+\underset{(3.87)}{0.026 I} \text { M fuel, }
$$

Adj R-squared $=0.63$, Number of obs. $=117$, Significance $-2 \%$.

where DEMvol - standard deviation of the index of political rights in 1972-2002.

Another indicator of the instability of democracy, more suited for our purposes, is AUTlast_min, the ratio of the index of political rights in 2002 to it's minimum value in the period 1972-2002. As explained before, it is a measure of the success of democratization: the closer it is to 1 , the less pronounced was the retreat from the highest point of democracy in the whole period.

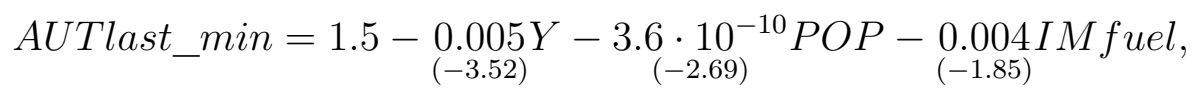

Adj R-squared $=0.09$, Number of obs. $=103$, Significance $-7 \%$.

where $P O P$ - population of a country in 1999.

The equation can be improved by adding control variables - such as the initial level of democracy in 1972-75, D, and the index of investment climate for 1984-90, IC, that is used as a proxy measurement of the institutional quality (in the later case POP becomes insignificant):

$$
\text { AUTlast_min }=2.5-\underset{(-1.79)}{0.005 Y}-\underset{(-1.73)}{0.009 I C}-\underset{(-2.21)}{0.1} D-\underset{(-2.20)}{0.006 I} \text { M fuel. }
$$

Adj R-squared $=0.17$, Number of obs. $=89$, Significance $-7 \%$.

Thus, it turns out that, controlling for the initial level of democracy, the magnitude of the democratic retreat that occurred in 1972-2002 was greater in relatively poor countries with weaker institutions and larger resource exports. 
The equation also works, if the quality of institutions is measured by the various indices for the end of the period in question, such as the rule of law index and voice and accountability index, but we do not report these regressions because they suffer from endogeneity (institutional indices for the end of the period are themselves influenced by the trends in democracy). Besides, the regression works with the increase in "cleanness" (as measured by the change in CPI - corruption perception index from Transparency International) from 1980-85 to 2002-03, but there may be the same endogeneity problem here.

It could also be that big government (high revenues of central government as a $\%$ of GDP in the beginning of the period) and smaller spending on defense during the period increases the chances of successful democratic transition:

$$
\begin{aligned}
\text { AUTlast_min } & =2.1-\underset{(-2.73)}{0.007 Y}-\underset{(-1.82)}{0.01} \operatorname{Rev}+\underset{(1.80)}{0.03 D e f}-\underset{(-2.50)}{0.008 \text { I M fuel },} \\
\text { Adj R-squared } & =0.20, \text { Number of obs. }=83, \text { Significance }-8 \% .
\end{aligned}
$$

where

Rev - average share of central government revenues in GDP in 1971-75, \%,

Def - average share of defense spending in 1980-99, \% of GDP.

The regression analysis corroborates our model predictions only partially. We have found that bad investment climate is a significant factor of instability of democratic regimes. However, corruption perception index does not show to be significant. This may be a result of using too rough measure of democracy instability.

Our empirical findings may be considered only as preliminary because some explanatory variables (especially, institutional indicators) may be endogenous, so more sophisticated analysis including panel regressions is needed for obtaining more reliable results.

The model developed above draws a complicated picture of how stability of democracy depends on institutional quality and resource abundance. More efforts are needed to study this picture in greater detail. 


\section{Conclusion}

In a number of previous papers, it was shown that an incumbent (a politician or a party) may keep its power using resource rent and institution weakness of a country. In this paper, we demonstrated that low institution quality and resource abundance lead to instability of democracy even if an incumbent does not pretend to autocratic power. This result is implied by political corruption and fundamental asymmetry that is typical for resource abundant market economies - concentration of resource wealth in hands of a small group of owners. The model predicts also that resource abundance does not threaten democracy if the institutional quality exceeds a threshold level and expected Autocrat's efficiency is not higher than the efficiency of democratic governments.

However, the suggested model has a number of limitations. First, we assumed that rent taxation has no impact on production. Second, expected Autocrat's efficiency was considered as exogenously given. Third, strategies announced by Autocrat were assumed to be credible. Whereas the first limitations may be overcome inside one period frameworks, two others require a multi-period model. These are important directions of further research.

\section{References}

Acemoglu, D., Robinson, J.A. and T.Verdier. (2003). Kleptocracy and Divide-and Rule: A Model of Personal Rule. NBER Working Series, Working Paper 10136. (http://www.nber.org/papers/w10136).

Acemoglu, A., Johnson, S., Robinson, J., and P. Yared (2005). Income and Democracy. MIT, Working paper 05-05, February, 35 pp.

Akhmedov, A., and E. Zhuravskaya (2004). Opportunistic Political Cycles: Test in a Young Democracy Setting. - Quarterly Journal of Economics, November 2004, 1301- 1338.

Alexeev, M. and R. Conrad (2005) "The elusive curse of oil." Working Papers Series, SAN05-07.

Auty, R.M. (ed.), (2001), Resource Abundance and Economic Development, Oxford University Press, 340 pp. 
Barro, R. J., 1996, Democracy and Growth. Journal of Economic Growth, Vol.1, 3-27

Barro, R.J., 1999, Determinants of Democracy, The Journal of Political Economy, vol. 107, No. 6, Part. 2.

Brunnschweiler, C. N. (2006) "Cursing the blessings? Natural resource abundance, institutions, and economic growth." Economics Working Paper Series 06/51, ETH Zurich.

Bulte, E.H. R. Damania, and R. T. Deacon (2003), Resource Abundance, Poverty and Development. Working paper, Department of Economics, University of California, Santa Barbara. (http://www.econ.ucsb.edu/papers/wp21-03.pdf).

Carothers, Thomas (2002). The End of the Transition Paradigm. - Journal of Democracy, Jan. 2002, pp.5-21.

Clague, Ch., Keefer, Ph., Knack, St., and M. Olson (1996). Property and Contract Rights in Autocracies and Democracies. Journal of Economic Growth, Vol.1, (June), 243276.

Chistyakov, E. ( 2006). Natural Resources, Corruption, and Manufacturing in Small Open Economy. Master's Thesis. New Economic School. Moscow. (Manuscript).

Diamond, L. J. Thinking About Hybrid Regimes. Journal of Democracy - Volume 13, Number 2, April 2002, pp. 21-35.

Egorov, G., Guriev, S. and K. Sonin (2006). Media Freedom, Bureaucratic Incentives, and the Resource Curse. CEDI Working Paper No. 06-10, (http://cedi.org.uk).

Geveling, L. (2001). Kleptocracy. M.: Academy of Humanitarian Research. 592pp. (in Russian).

Kartashov, G. (2006) "Economic growth and institutional quality in resource oriented countries." (in Russian). Master's Thesis. New Economic School, Moscow. (Manuscript).

Leite C. and J. Weidmann (1999). "Does Mother Nature Corrupt? Natural Resources, Corruption, and Economic Growth." IMF Working Paper No. 99/85.

Mehlum, H., K.O. Moene and R. Torvik (2005) "Institutions and the resource curse." Economic Journal, Royal Economic Society 116(508): 1-20.

Polterovich, V. and Popov, V. (2006). Democratization, Quality of Institutions and 
Economic Growth, Working Paper \#2006/056.

Robinson, J.A., R. Torvik and T. Verdier (2006). "Political foundations of the resource curse." Journal of Development Economics 79: 447-468.

Rodriguez, F. and J.D.Sachs (1999). Why do resource abundant economies grow more slowly? A new explanation and an application to Venezuela, Journal of Economic Growth, 4, 277-303.

Ross, M.L. (2001). Does Oil Hinder Democracy? World Politics 53 (April 2001), 32561.

Sachs, J.D. and A.M. Warner (1999). The big push, natural resource booms and growth.

Journal of Development Economics, vol.59, 43-76.

Sachs, J.D. and A.M. Warner (2001). "The curse of natural resources." European

Economic Review 45: 827-838.

Stiglitz, J.E. (2004). The Resource Curse Revisited, Project Syndicate. (http://www.project-syndicate.org/commentaries/ commentary_text.php4?id=1656\&lang $=1 \& \mathrm{~m}=$ contributor $)$.

Stijns P.C. (2005). "Natural resource abundance and economic growth revisited." Mimeo, Department of Economics, UC Berkeley.

Tornell A., and Lane P.R. (1999). "The voracity effect." American Economic Review 89: $22-46$.

Torvik, R. (2002). "Natural resources, rent seeking and welfare." Journal of Development Economics 67: 455-470.

Wantchekon, L. (1999). Why do Resource Dependent Countries Have Authoritarian Governments? Yale University, 24 pp. (http://www.yale.edu/leitner/pdf/1999-11.pdf).

Wantchekon, L., and E. Yehoue (2002). Crime in New Democracies. 24 pp. (http://www.nyu.edu/gsas/dept/politics/faculty/wantchekon/research/crime.pdf).

Wintrobe, R (2007). Dictatorship: Analytical Approaches, in: C.Boix and S. Stokes, Oxford Handbook of Comparative Politics, Oxford University Press, 2007. 
Zhukova, N. ( 2006). Institutions and Optimal Level of Resources in Resource Abundant Countries. Master's Thesis. New Economic School, Moscow. (Manuscript).

\section{Appendix}

Proof of Proposition 2(b). If $\gamma \geq \bar{\gamma}$, then $\Delta<0$ and the objective function in (23) is convex in $\tau$ for $\tau \in\left[e\left(\underline{\tau}\left(\tau^{0}\right)\right), e\left(\bar{\tau}\left(\tau^{0}\right)\right)\right]$. Moreover, as follows from (26), $V\left(\bar{\tau}\left(\tau^{0}\right), \tau^{0}\right)<V\left(1, \tau^{0}\right)$ in this case. Hence, a maximum in (23) is reached either at $\tau=0$ or at $\tau=1$. One of the following four cases is possible:

Case 1: $\underline{\tau}\left(\tau^{0}\right) \leq 0, \bar{\tau}\left(\tau^{0}\right) \leq 1$. The first of the two conditions implies that

$$
A \leq \frac{m}{\xi_{2} \tau^{0} h} \leq \frac{1}{\xi_{2} \tau^{0} h}
$$

Both conditions imply that

$$
\begin{aligned}
& V\left(1, \tau^{0}\right)-V\left(0, \tau^{0}\right) \geq V\left(\bar{\tau}\left(\tau^{0}\right), \tau^{0}\right)-V\left(0, \tau^{0}\right)= \\
& =\left(\gamma(\lambda-1)-\frac{\Delta}{\xi_{1} h}+\tau^{0} \tilde{\Delta} A\right)\left(1-m+\xi_{2} \tau^{0} h A\right)
\end{aligned}
$$

As follows from (42), $V\left(1, \tau^{0}\right)>V\left(0, \tau^{0}\right)$, if $\tilde{\Delta} \geq 0$. Suppose that $\tilde{\Delta}<0$. Then, due to $(41)$ and $(16)$,

$$
\tau^{0} \tilde{\Delta} h A-\frac{\Delta}{\xi_{1}} \geq \frac{1}{\xi_{2}}-\frac{1}{\xi_{1}}+\gamma(\lambda-1) \geq \frac{1}{\xi_{2}}-\frac{\lambda}{\xi_{2}}+\gamma(\lambda-1)=\frac{(1-\lambda) \tilde{\Delta}}{\xi_{2}}>0 .
$$

Combining (42) and (43), we obtain $V\left(1, \tau^{0}\right)>V\left(0, \tau^{0}\right)$.

Case 2: $\underline{\tau}\left(\tau^{0}\right) \leq 0, \bar{\tau}\left(\tau^{0}\right)>1$.. In this case, (41) holds and

$$
\frac{V\left(1, \tau^{0}\right)-V\left(0, \tau^{0}\right)}{A}=k h A-\Delta m+\gamma(\lambda-1) \xi_{1} h
$$

where

$$
k=\tilde{\Delta} \xi_{1} \tau^{0}+\Delta\left(\xi_{2} \tau^{0}-\xi_{1}\right) .
$$

If $k \geq 0$, then the right-hand side of (44) is obviously positive. Suppose that $k<0$. Then the right-hand side of (44) is decreasing in $A$. Using (41) and the inequality $\tilde{\Delta}>\Delta$, we obtain

$$
k h A \geq k h \frac{m}{\xi_{2} \tau^{0} h}>-\Delta\left(\frac{\xi_{1}}{\xi_{2}}\left(\frac{1}{\tau^{0}}-1\right)-1\right) m \geq \Delta m .
$$

Combining (44) and (46), we obtain $V\left(1, \tau^{0}\right)>V\left(0, \tau^{0}\right)$. 
Case 3: $\underline{\tau}\left(\tau^{0}\right)>0, \bar{\tau}\left(\tau^{0}\right) \leq 1$. In this case,

$$
V\left(1, \tau^{0}\right)-V\left(0, \tau^{0}\right)=\left(\gamma \tau^{0}\left(\lambda \xi_{1}-\xi_{2}\right)-\left(1-\tau^{0}\right) \Delta\right) A+\gamma(\lambda-1)>0
$$

Case 4: $\underline{\tau}\left(\tau^{0}\right)>0, \bar{\tau}\left(\tau^{0}\right)>1$. In this case,

$$
V\left(1, \tau^{0}\right)-V\left(0, \tau^{0}\right)=\left(\left(\tau^{0} \tilde{\Delta}-\Delta\right) A+\gamma(\lambda-1)\right)\left(p\left(1, \tau^{0}\right)+(1-\tau) \xi_{1} h A\right)
$$

Since $\Delta<0$ and $\tilde{\Delta}>\Delta$, then the right-hand side of (48) is positive.

We have seen that in any case, $V\left(1, \tau^{0}\right)>V\left(0, \tau^{0}\right)$, so $\tau=1$ is a solution to $(23)-(24)$ for $\gamma \geq \bar{\gamma}$. 